\title{
Failure Mode and Fatigue Behavior of Weld-Bonded Lap-Shear Specimens of Magnesium and Steel Sheets
}

\author{
Wei-Jen Lai ${ }^{a}$ and Jwo Pan ${ }^{\mathrm{b}}$ \\ ${ }^{\text {a }}$ Department of Materials Science and Engineering \\ The University of Michigan \\ Ann Arbor, MI, 48109, USA \\ ${ }^{\mathrm{b}}$ Department of Mechanical Engineering \\ The University of Michigan \\ Ann Arbor, MI, 48109, USA \\ December 30, 2014
}

\begin{abstract}
Failure modes and fatigue behaviors of ultrasonic spot welds in lap-shear specimens of magnesium AZ31B-H24 and hot-dipped-galvanized mild steel sheets with and without adhesive were investigated. The spot welded specimens failed from the kinked crack growth mode. The adhesive-bonded specimens failed from the cohesive failure through the adhesive and the kinked crack growth through the magnesium sheet. The weld-bonded specimens failed from the cohesive failure through the adhesive, the interfacial failure through the spot weld, and the kinked crack growth through the magnesium sheet. The estimated fatigue lives for the adhesive-bonded and weldbonded specimens failed from the kinked crack growth mode are lower than the experimental results.
\end{abstract}

\section{Keywords}

Ultrasonic spot weld; adhesive-bonded; weld-bonded; magnesium; fatigue life estimation

\section{Introduction}

Lightweight materials such as advanced high strength steels, aluminum, and magnesium alloys have been replacing the traditional steel in the automotive industry to reduce the vehicle weight for better fuel efficiency. Since magnesium alloys are much lighter than the steels commonly used in vehicles, using magnesium alloys could result in a substantial weight reduction. One of the major issues for introducing magnesium alloys into vehicle structures appears to be joining magnesium components to the existing steel structures. Joining magnesium alloys to

Corresponding author. Tel.:+1-734-764-9404; fax:+1-734-647-3170.

Email addresses: weijen@umich.edu (W.-J. Lai), jwo@umich.edu (J. Pan). 
steels is especially difficult due to the extreme difference in their melting temperatures and immiscibility of magnesium and iron [1]. Melting magnesium alloys and steels together as might be done in resistance spot welding would vaporize magnesium and create unacceptable porosity in the weld nugget. Solid state joining of magnesium alloys and steels offers a potential solution as the melting is either avoided or minimized. Both friction stir spot welding (FSSW) and ultrasonic spot welding (USW) are capable of joining similar and dissimilar materials. A comprehensive review of FSSW on joining similar materials can be found in Pan [2]. The research works on joining dissimilar materials by FSSW were carried out mostly on joining aluminum and steel sheets, for example, see Gendo et al. [3]. Liyanage et al. [4] conducted research on joining magnesium to steel sheets by FSSW with tool penetration into the lower steel sheets by using a tungsten-based W-25Re tool. However, it would be difficult to implement the technology in the mass production due to tool wear.

For joining similar materials using USW for automotive applications, researchers conducted research on processing conditions of joining similar aluminum sheets, for example, see Hetrick et al. [5], Jahn et al. [6] and Wright et al. [7]. For joining dissimilar sheets by USW, Watanabe et al. [8] investigated the effects of the welding conditions and insert metal on the mechanical properties of dissimilar joints of aluminum and steel sheets. Santella et al. [1] investigated the effects of the zinc coating on joining magnesium to zinc-coated steel sheets by USW. Shakil et al. [9] conducted research on the effects of the welding parameters on microstructure and mechanical properties of dissimilar joints of aluminum and stainless steel sheets by USW. Matsuoka and Imai [10] conducted research on the effects of the welding parameters on joining aluminum and copper sheets by USW. The fatigue behavior of dissimilar ultrasonic spot welds in lap-shear specimens of magnesium AZ31B-H24 and hot-dippedgalvanized mild steel sheets was investigated by Franklin et al. [11]. For joining similar materials using ultrasonic weld bonding (USW + adhesive), Carboni and Moroni [12] conducted research on joining aluminum and magnesium sheets by ultrasonic weld bonding and found better fatigue performance than the ones made by USW alone.

The introduction of pre-cracks in the adhesive-bonded lap-shear specimen was motivated by the computational results reported by Heyes et al. [13], who intentionally introduced pre-cracks in their finite element models of the adhesive-bonded specimens to evaluate the $J$ integrals for the pre-cracks. Their computational results show that the $J$ integral for the pre-cracks can be used to correlate the fatigue lives of different types of specimens. In this investigation, pre-cracks were intentionally introduced in adhesive-bonded and weld-bonded lap- 
shear specimens. The existence of the stress and strain singularities near the pre-cracks benefits the fatigue life estimation in a way such that the fatigue initiation life can be assumed to be short and then neglected. The fatigue life can therefore be estimated by considering only the crack propagation life using the Paris law.

In this paper, the failure modes and fatigue behaviors of ultrasonic spot welded, adhesive-bonded, and weld-bonded lap-shear specimens of dissimilar magnesium AZ31B-H24 sheets and galvanized mild steel sheets are examined. Ultrasonic spot welded, adhesive-bonded, and weld-bonded lap-shear specimens were first made from dissimilar magnesium AZ31B-H24 sheets and galvanized mild steel sheets. These lap-shear specimens were then tested under quasi-static and cyclic loading conditions. Quasi-static and fatigue strengths of the three types of joints in lap-shear specimens were then obtained. Optical micrographs and SEM images of the failed joints after testing are also examined to identify the failure modes of the joints. Based on the failure modes, fatigue lives of the specimens failed in the kinked crack failure mode are estimated using the Paris law. Finally, conclusions are made based on the experimental results.

\section{Experiment}

Magnesium AZ31B-H24 and hot-dip-galvanized (HDG) mild steel sheets with the thicknesses of $1.6 \mathrm{~mm}$ and $0.8 \mathrm{~mm}$, respectively, were used in this investigation. First, tensile tests were conducted using a MTS Insight testing machine with a $10 \mathrm{kN}$ load cell at the University of Michigan. An extensometer was used for all specimens with a gauge length of $50.8 \mathrm{~mm}$. The ASTM E8/E8M-11 tensile specimen standard for sheet materials was adopted. Figure 1(a) shows a schematic of a tensile specimen with the dimensions. Figure 1(b) shows the tensile specimens of the magnesium and steel sheets from the top to the bottom, respectively. The displacement rate was set at 2.54 $\mathrm{mm} / \mathrm{min}$ (nominal strain rate of $0.00085 \mathrm{~s}^{-1}$ ) for all tensile specimens. Three specimens were tested for each material. The stress-strain curves of the magnesium and steel sheets are shown in Figure 2. It is noted that the magnesium shows low strain hardening after yielding. The total elongation ranges from 13 to $22 \%$ for the three specimens. The steel sheet shows higher strain hardening after yielding. However, due to the extension limit of the extensometer, the tests were conducted up to the nominal strain of $40 \%$ for the steel sheets. Table 1 lists the elastic moduli, yield stresses, and tensile strengths of the magnesium and steel sheets.

Ultrasonic spot welded (USW), adhesive-bonded, and weld-bonded (ultrasonic spot welded and adhesivebonded) lap-shear specimens were prepared for this study. Each lap-shear specimen was made by a $30 \mathrm{~mm} \times 100$ 
$\mathrm{mm}$ magnesium sheet and a $30 \mathrm{~mm} \times 100 \mathrm{~mm}$ HDG steel sheet with a $30 \mathrm{~mm} \times 40 \mathrm{~mm}$ overlap area. Figure 3(a) shows the top views of the USW, adhesive-bonded, and weld-bonded lap-shear specimens from the top to the bottom. Figures 3(b) to 3(d) show schematics of the top and the side views of USW, adhesive-bonded, and weldbonded lap-shear specimens with doublers. In the figures, the loading direction is shown by the arrows. The adhesive is shown as the red lines in Figures 3(c) and 3(d) for the adhesive-bonded and weld-bonded lap-shear specimens.

For the USW lap-shear specimens, a Sonobond CLF 2500 single-transducer, wedge-reed ultrasonic welder was used for the ultrasonic spot welding. The sonotrode tip has a square face of $7 \mathrm{~mm} \times 7 \mathrm{~mm}$ and the face has a grooved pattern. The ultrasonic spot welding was done with a power of $1500 \mathrm{~W}$, an impedance setting of 6 , and a welding time of $2.1 \mathrm{~s}$. The spot welding was centered in the overlap area. Figure 3(a) shows the indentation of the sonotrode tip on the upper magnesium of the USW specimen. The microstructures of the sheets, the specimen preparation procedure, and the processing conditions for the USW lap-shear specimens were detailed in Santella et al. [1].

For the adhesive-bonded lap-shear specimens, the magnesium and steel sheets were bonded by BETAMATE ${ }^{\mathrm{TM}} 73305$, a one-part heat-curing epoxy adhesive. Prior to applying the adhesive, two tapes were placed on the magnesium and steel sheets to form two pre-cracks between the sheets and the adhesive, as shown in Figure 3(a). The locations of the tape tips are indicated in Figure 3(c). As shown in the figure, the tape tips are 5 $\mathrm{mm}$ from the edges of the overlap region. The adhesive thickness is controlled by placing a few 0.3 -mm zirconia balls on the bonded surfaces. Hence the final adhesive thickness is $0.3 \mathrm{~mm}$. The specimen was then heated to the curing temperature to join the sheets. The area joined by the adhesive is $30 \mathrm{~mm} \times 30 \mathrm{~mm}$ which is smaller than the overlap area of the two sheets.

For the weld-bonded lap-shear specimens, the adhesive was first applied and then the sheets were ultrasonic spot welded. The ultrasonic spot welding procedure is the same as that for the USW lap-shear specimens. Figure 3(a) also shows the indentation of the sonotrode tip on the upper magnesium sheet of the weld-bonded specimen. Two tapes were also placed on the magnesium and steel sheets to form two pre-cracks between the sheets and the adhesive, as those for the adhesive-bonded specimen. Each welded specimen was then heated to the curing temperature to further join the rest of the overlap region. 


\section{Quasi-static and fatigue test results}

The results of the quasi-static tests indicate that the failure load per bonded area for USW lap-shear specimens is higher than that for adhesive-bonded lap-shear specimens. However, the adhesive-bonded and weldbonded lap-shear specimens have almost the same failure load. It appears that the ultrasonic welds do not provide significant extra strength to the weld-bonded joints. A possible reason is the poor weld quality since the thickness of the adhesive layer was controlled and limited by the zirconia balls between the magnesium and steel sheets such that the sheets cannot have good surface contact during the welding process. Under cyclic loading conditions, the adhesive-bonded and weld-bonded specimens have longer fatigue lives than those of the USW specimens for given load ranges. Also, adhesive-bonded and weld-bonded lap-shear specimens appear to have the same load range-life curves. This further confirms that the ultrasonic spot weld in the weld-bonded lap-shear specimen does not contribute to additional joint fatigue lives for given load ranges.

\section{Failure mode}




\subsection{USW lap-shear specimen}

An overview of the failure modes of ultrasonic spot welds in the lap-shear specimen is schematically shown in Figure 5. Figure 5(a) shows a schematic of the symmetry cross section near the ultrasonic spot weld. The thin solid lines represent the fracture surface or fatigue crack. Figure 5(b) shows a table that summarizes the failure modes under quasi-static, low-cycle, high-cycle high-load and high-cycle low-load loading conditions. As schematically shown in the figure, the weld fails in a partial nugget pullout failure mode with the fracture surfaces A and B1 through the magnesium sheet under quasi-static loading conditions. Under low-cycle loading conditions, the weld fails in the kinked crack failure mode with a crack $\mathrm{C}$ growing through the magnesium sheet and partial nugget pullout with the fracture surface B2. Under high-cycle high-load loading conditions, the weld fails from a kinked crack E growing through the magnesium sheet and finally fails along the interface D. Under high-cycle low-load loading conditions, the weld fails in the kinked crack failure mode with a crack E and finally fails in a transverse crack growing through the specimen width. The details of the failure modes will be explained by the micrographs in the following.

Figure 6(a) shows the symmetry cross section near the ultrasonic spot weld in an untested specimen as a reference. As shown in the figure, the weld is asymmetric since the specimen was not constrained during the welding (Santella et al. [1]). Under quasi-static loading conditions, the experimental observations indicate that the ultrasonic spot welds failed in a partial nugget pullout failure mode. Figure 6(b) shows the top view of the upper magnesium sheet and the top view of the lower steel sheet near a failed weld under quasi-static loading conditions from the top to the bottom. As shown in the lower figure, the failed weld has a partial nugget of the upper magnesium left on the lower steel sheet. Figure 6(c) shows the symmetry cross section of the failed weld shown in Figure 6(b) with a nearly full nugget left on the lower steel sheet. It is noted that the fracture took the shortest path from the right interface crack tip to the corner of the indentation.

Under low-cycle loading conditions for the fatigue lives from $3 \times 10^{2}$ to $3 \times 10^{3}$ cycles, the experimental observations indicate that the specimens mainly failed in the kinked crack failure mode with the kink angle close to $90^{\circ}$. Figure 6(d) shows the top view of the upper magnesium sheet and the top view of the lower steel sheet near a failed weld under low-cycle loading conditions at the fatigue life of $1.2 \times 10^{3}$ cycles under the load range of $2,844 \mathrm{~N}$ from the top to the bottom. As shown in the lower figure, the failed weld also has a partial nugget of the upper magnesium left on the lower steel sheet. Figure 6(e) shows the symmetry cross section of the failed weld shown in 


\subsection{Adhesive-bonded lap-shear specimen}

An overview of the failure modes of adhesive-bonded lap-shear specimens is schematically shown in Figure 7. Figures 7(a) and 7(b) show the cohesive failure mode near the interface between the steel and adhesive under quasi-static and low-cycle loading conditions, respectively. Figure 7(c) shows the kinked crack failure mode in the magnesium sheet under high-cycle loading conditions. The details of the failure modes will be explained by the micrographs in the following. Note that the brightness and contrast of the adhesive layers shown in Figures $8(\mathrm{a}$, 

were painted black.

Figure 8(a) shows the symmetry cross section near the joint in an untested adhesive-bonded lap-shear specimen as a reference. Under quasi-static loading conditions, the experimental observations indicate that the adhesive-bonded joint failed in the cohesive failure mode near the interface between the steel and adhesive. Figure 8(b) shows the bottom view of the upper magnesium sheet and the top view of the lower steel sheet for a failed joint under quasi-static loading conditions from the top to the bottom. Figure 8(c) shows the symmetry cross section of the failed joint shown in Figure 8(b). Figure 7(a) shows a schematic of the near interface cohesive failure mode of the specimen under quasi-static loading conditions. The crack appears to grow in the adhesive but close to the interface between the steel and adhesive, as shown with a lighter gray area on the top view of the lower steel sheet in Figure 8(b). An interrupted test of the adhesive-bonded lap-shear specimen was conducted under quasi-static loading conditions at the load of 5,500 $\mathrm{N}$ ( $85 \%$ of the failure load). As shown in the micrographs taken from the symmetry cross section of the partially failed specimen, the crack grew from the left tape tip due to the extensive plastic deformation of the steel sheet and no crack growth was observed near the right tape tip. Therefore, the fracture/separation near the right tape tip as shown in Figures 7(a) and 8(c) appears to be corresponding to the final fracture of the specimen.

Under low-cycle loading conditions for the fatigue lives from $3 \times 10^{3}$ to $10^{4}$ cycles, the experimental observations indicate that the adhesive also failed in the near interface cohesive failure mode. Figure 8(d) shows the bottom view of the upper magnesium sheet and the top view of the lower steel sheet for a failed joint under lowcycle loading conditions at the fatigue life of $6.3 \times 10^{3}$ cycles under the load range of 5,200 $\mathrm{N}$ from the top to the bottom. As shown in Figure 8(d), the crack on the left side grew initially about $10 \mathrm{~mm}$ in the scattered cohesive failure mode due to the loading of the first cycle to the high maximum load. The failure mode due to the first cycle shows the scattered cohesive failure (partial interfacial and partial cohesive failure) possibly due to the higher strain rate because the fracture surface is different from that of the near interface cohesive failure observed in the specimen under quasi-static loading conditions. In the following fatigue cycles, the crack grew from the new crack front which corresponds to the starter crack tip as schematically marked in Figure 7(b). Figure 7(b) shows a schematic of the near interface cohesive failure mode of the specimen under low-cycle loading conditions. Note the failure mode changes from the scattered cohesive failure to the near interface cohesive failure near the beginning of the cyclic 
crack growth. Figure 8(e) shows the symmetry cross section of the failed joint shown in Figure 8(d). An interrupted test of an adhesive-bonded lap-shear specimen was conducted under low-cycle loading conditions at the fatigue life of 1,500 cycles under the load range of 5,200 N. As shown in the micrographs taken from the symmetry cross section of the partially failed specimen, the crack grew from the left tape tip and no crack growth was observed near the right tape tip. Therefore, the fracture/separation near the right tape tip as shown in Figures 7(b) and 8(e) appears to be corresponding to the final fracture of the specimen.

Under high-cycle loading conditions for the fatigue lives from $10^{4}$ to $10^{5}$ cycles, the experimental observations indicate that the specimens failed in the kinked crack failure mode. Figure 8(f) shows the bottom view of the upper magnesium sheet and the top view of the lower steel sheet for a failed joint under high-cycle loading conditions at the fatigue life of $3.6 \times 10^{4}$ cycles under the load range of $4,222 \mathrm{~N}$ from the top to the bottom. Figure 8(g) shows the symmetry cross section of the failed joint shown in Figure 8(f). As shown in the figure, a kinked crack was initiated from the right tape tip and grew up into the magnesium sheet at an angle of about $30^{\circ}$. Once it reached a critical kink length, the kinked crack turned to $90^{\circ}$ and grew into the upper magnesium sheet. The $30^{\circ}$ kinked crack was observed in all the specimens failed in the magnesium sheet.

Figures 9(a) to 9(d) show the fracture surfaces of the upper right magnesium sheets of four failed specimens under different load ranges. Note that significant variation in the geometries of the kinked cracks was observed from these fracture surfaces. However, there is a general trend of increasing kink length with decreasing load range, as indicated by the red arrow pairs in the figure. Also, the $90^{\circ}$ crack after the $30^{\circ}$ kinked crack was observed for all the specimens, as indicated by the white arrow pairs in the figure. Note that the geometries of the $90^{\circ}$ cracks also vary significantly across the fracture surfaces. Finally, when the average stress in the remaining magnesium cross section reached about the tensile strength of the magnesium sheets, the magnesium sheets appeared to fail in shear with various angles inclined to the surface of the specimen sheets as observed in those of the failed magnesium sheet specimen under uniaxial tensile loading conditions. The final fracture surfaces are also marked in the figures.

Figures 10(a) and 10(b) show SEM images of the $30^{\circ}$ kinked crack surface of the upper right magnesium sheet of a failed specimen at low and high magnifications, respectively, under cyclic loading conditions at the fatigue life of $2.5 \times 10^{4}$ cycles under the load range of $4,080 \mathrm{~N}$. The fatigue striations can be clearly seen in Figure 10(b) and are in general perpendicular to the crack growth direction. Figures 10(c) and 10(d) show SEM images of 

is noted that no dimple was observed on the fracture surface. The formation of the $90^{\circ}$ crack is possibly due to reaching the fracture resistance of the magnesium [14]. Figure 10(e) shows an SEM image of the final fracture surface of the upper right magnesium sheet of a failed specimen under cyclic loading conditions at the fatigue life of $2.5 \times 10^{4}$ cycles under the load range of 4,080 N. Figure $10(\mathrm{e})$ shows a typical ductile fracture surface with dimples. Note that Figure 7(c) shows a schematic of the kinked crack failure mode under high-cycle loading conditions. It was observed that the left crack on the steel side grew a bit but did not cause the final failure for the load ranges that are close to those under low-cycle loading conditions. Note that the low-cycle and high-cycle loading conditions in this study are defined based on the failure modes only for convenient presentation of the experimental results.

Under both quasi-static and cyclic loading conditions, large plastic deformation in the steel sheet due to bending near the crack tip was observed. The large plastic deformation in the steel sheet is due to the low yield strength and the relative small thickness under the given lap-shear loads. As the crack grew, the large plastic deformation moved along with the crack front under both quasi-static and cyclic loading conditions. Figures 11(a) and 11(b) show the bottom views of the lower steel sheets under quasi-static and low-cycle loading conditions, respectively. Figure 11(a) shows the plastic deformation patterns of the steel sheets along the crack fronts in the failed and partially failed specimens under quasi-static loading conditions. The partially failed specimen was under the load at $85 \%$ of the failure load. Figure 11(b) shows the plastic deformation patterns of the steel sheets along the crack fronts in the failed specimen under low-cycle loading conditions at the fatigue life of 3,462 cycles under the load range of 5,560 $\mathrm{N}$ and a partially failed specimens under low-cycle loading conditions at the fatigue life of 1,500 cycles under the load range of 5,200 N. As shown in both figures, the plastic deformation along the crack fronts of the failed specimens is closer to the right compared to that for the partially failed specimen. Note that the crack grew from the left tape tip to the right tape tip for both cases. Finally, it is noted that a small amount of necking was also observed in the steel sheets of the failed specimens in the width direction as shown in Figure 11. 


\subsection{USW + adhesive (weld-bonded) lap-shear specimen}

An overview of the failure modes of weld-bonded lap-shear specimens is schematically shown in Figure 12. Figures 12(a) and 12(b) show the cohesive failure mode near the interface between the steel and adhesive and the interfacial failure mode of the ultrasonic spot weld under quasi-static and low-cycle loading conditions, respectively. Figure 12(c) shows the kinked crack failure mode in the magnesium sheet under high-cycle loading conditions. The details of the failure modes will be explained by the micrographs in the following. Note that the brightness and contrast of the adhesive layers shown in Figures 13(a, c, e, g) were selectively adjusted to highlight their geometries and details. Also, the backgrounds in these figures were painted black.

Figure 13(a) shows the symmetry cross section near the ultrasonic spot weld of the joint in an untested weld-bonded lap-shear specimen as a reference. The micrograph indicates that the adhesive was pushed out during the ultrasonic spot welding process. However, several circular holes appear along the interface in the ultrasonic spot weld. These holes are from the zirconia balls. A small portion of a zirconia ball can be seen in one of the holes. Under quasi-static loading conditions, the experimental observations indicate that the weld-bonded joint failed in the cohesive failure mode near the interface between the steel and adhesive and the interfacial failure mode of the ultrasonic spot weld. Figure 13(b) shows the bottom view of the upper magnesium sheet and the top view of the lower steel sheet for a failed joint under quasi-static loading conditions from the top to the bottom. The failure mode is similar to that for the adhesive-bonded lap-shear specimen as shown in Figure 8(b). Figure 13(b) shows some residual adhesive on the interface of the ultrasonic spot weld. The residual adhesive suggests that the weld quality is not good and does not provide good bonding strength. Figure 13(c) shows the symmetry cross section of the failed joint shown in Figure 13(b). Figure 12(a) shows a schematic of the failure mode of the specimen under quasi-static loading conditions. As shown in the figure, the crack grows in the adhesive but close to the interface between the steel and adhesive. Figure 12(a) also shows an interfacial failure mode for the ultrasonic spot weld. An interrupted test of the weld-bonded lap-shear specimen was conducted under quasi-static loading conditions at the load of 5,500 $\mathrm{N}(85 \%$ of the failure load). As shown in the micrographs taken from the symmetry cross section of the partially failed specimen, the crack grew from the left tape tip due to the extensive plastic deformation of the steel sheet and no crack growth was observed near the right tape tip. Therefore, the fracture/separation near the right tape tip as shown in Figures 12(a) and 13(c) appears to be corresponding to the final fracture of the specimen. 
Under low-cycle loading conditions for the fatigue lives from $3 \times 10^{3}$ to $3 \times 10^{4}$ cycles, the experimental observations indicate that the adhesive failed in the near interface cohesive failure mode and the ultrasonic spot weld failed in an interfacial failure mode. Figure 13(d) shows the bottom view of the upper magnesium sheet and the top view of the lower steel sheet for a failed joint under low-cycle loading conditions at the fatigue life of $1.4 \times 10^{4}$ cycles under the load range of 5,138 $\mathrm{N}$ from the top to the bottom. Figure 13(d) shows that the crack on the left side grew initially about 10 to $20 \mathrm{~mm}$ unevenly to the right. This initial crack growth was due to the loading of the first cycle to the high maximum load. The failure mode due to the first cycle shows the scattered cohesive failure (partial interfacial and partial cohesive failure) possibly due to the higher strain rate because the fracture surface is different from that of the near interface cohesive failure observed in the specimen under quasi-static loading conditions. In the following fatigue cycles, the crack grew from the new crack front which corresponds to the starter crack tip as marked in Figure 12(b). Figure 13(e) shows the symmetry cross section of the failed joint shown in Figure 13(d). Note that some residual adhesive on the interface of the ultrasonic spot weld can be seen. Figure 12(b) shows a schematic of the near interface cohesive failure mode of the specimen and the interfacial failure mode of the ultrasonic spot weld under low-cycle loading conditions. Note the failure mode changes from the scattered cohesive failure to the near interface cohesive failure near the beginning of the cyclic crack growth. An interrupted test of a weld-bonded lap-shear specimen was conducted under low-cycle loading conditions at the fatigue life of 2,000 cycles under the load range of 5,240 N. As shown in the micrographs taken from the symmetry cross section of the partially failed specimen, the crack grew from the left tape tip and no crack growth was observed near the right tape tip. Therefore, the fracture/separation near the right tape tip as shown in Figures 12(b) and 13(e) appears to be corresponding to the final fracture of the specimen.

Under high-cycle loading conditions for the fatigue lives from $10^{4}$ to $10^{5}$ cycles, the experimental observations indicate that the specimens failed in the kinked crack failure mode. Figure 13(f) shows the bottom view of the upper magnesium sheet and the top view of the lower steel sheet for a failed joint under high-cycle loading conditions at the fatigue life of $7.1 \times 10^{5}$ cycles under the load range of 3,202 $\mathrm{N}$ from the top to the bottom. Figure 13(g) shows the symmetry cross section of the failed joint shown in Figure 13(f). As shown in the figure, several zirconia balls are shown along the interface in the ultrasonic spot weld. As shown in the figure, a kinked crack was initiated from the tape tip and grew up into the magnesium sheet at an angle of about $30^{\circ}$. Once it reached a critical kink length, the kinked crack turned to $90^{\circ}$ and grew into the upper magnesium sheet. Note that Figure 


\section{Fatigue life estimation}

The fatigue life estimations for the ultrasonic spot welds failed in the kinked crack failure mode in lapshear specimens of magnesium and steel sheets were discussed in Franklin [15]. The fatigue life estimation for the adhesive-bonded and weld-bonded lap-shear specimens failed in the kinked crack failure mode in the magnesium sheets under high-cyclic loading conditions are discussed here. Since the ultrasonic spot weld is relatively weak in the weld-bonded joint, the weld-bonded joint can be treated as the adhesive-bonded joint for fatigue life estimation.

The fatigue life estimations of the lap-shear specimens are based on the Paris law for crack growth and the stress intensity factor solutions obtained from the finite element analyses. For the kinked crack failures in the lap- 

equivalent local stress intensity factor $k_{e}$ is defined in Broek [16] as

$$
k_{e}(a)=\sqrt{k_{I}(a)^{2}+\gamma k_{I I}(a)^{2}}
$$

where $k_{I}$ and $k_{I I}$ are the local mode I and mode II stress intensity factor solutions and $a$ is the kink length. $\gamma$ is an empirical constant to account for the sensitivity of materials to the mode II loading condition. For lack of any further information, $\gamma$ is assumed as 1 in this paper.

The local stress intensity factor $k_{\mathrm{I}}, k_{\mathrm{II}}$ and $k_{\mathrm{e}}$ solutions for kinked cracks with small and finite kink lengths in lap-shear specimens can be expressed in the normalized forms as

$$
\begin{aligned}
& k_{\mathrm{I}}(a)=f_{\mathrm{I}}\left(\frac{a}{t_{u}}\right) \cdot \frac{F}{b \sqrt{t_{u}}} \\
& k_{\mathrm{II}}(a)=f_{\mathrm{II}}\left(\frac{a}{t_{u}}\right) \cdot \frac{F}{b \sqrt{t_{u}}} \\
& k_{\mathrm{e}}(a)=\sqrt{k_{I}^{2}(a)+k_{I I}^{2}(a)}=f_{\mathrm{e}}\left(\frac{a}{t_{u}}\right) \cdot \frac{F}{b \sqrt{t_{u}}}
\end{aligned}
$$

where $F$ is the applied load, $t_{u}$ is the thickness of the upper magnesium sheet and $b$ is the width of the lap-shear specimen. $f_{\mathrm{I}}, f_{\mathrm{II}}$ and $f_{\mathrm{e}}$ are dimensionless geometric functions which depend on the normalized kink length $a / t_{u}$ for this particular set of the geometry and material combination of the lap-shear specimen. The dimensionless geometric function $f_{\mathrm{e}}$ for adhesively-bonded specimens with different normalized kink lengths were obtained from finite element analyses as detailed in Lai and Pan [14]. Figure 15(a) shows a schematic of a two-dimensional finite element model of the adhesive-bonded lap-shear specimen with the boundary and loading conditions. The geometry, the loading and the boundary conditions of the specimen are detailed in Lai and Pan [14]. In Figure 15(a), a kinked crack is shown to grow from the right main crack tip into the upper magnesium sheet. Based on the micrograph shown in Figure 8(g), the kink angle is selected to be $30^{\circ}$. Figure 15(b) shows a close-up view of the finite element mesh near the kinked crack for $a / t_{u}=0.1$. The computational results for the dimensionless geometric function $f_{\mathrm{e}}$ for thirteen normalized crack lengths are shown in Figure 16.

Now the Paris law is used to describe the fatigue crack propagation for the kinked crack as 
where $N$ is the life or number of cycles, $C$ and $m$ are material constants, and $\Delta k_{e}$ is the range of the equivalent local stress intensity factor as a function of the kink length $a$. Since the equivalent local stress intensity factor $k_{\mathrm{e}}$ solution is a function of the kink length $a$, the fatigue life of the adhesive-bonded/weld-bonded joints can be obtained by integrating Equation (5) as

$$
N=\frac{1}{C}\left\{\int_{0}^{a_{1}}\left[\Delta k_{e}(a)\right]^{-m} \mathrm{~d} a+\int_{a_{1}}^{a_{2}}\left[\Delta k_{e}(a)\right]^{-m} \mathrm{~d} a+\cdots+\int_{a_{i-1}}^{a_{i}}\left[\Delta k_{e}(a)\right]^{-m} \mathrm{~d} a\right\}
$$

where $a_{1}, a_{2}, \ldots$ and $a_{i}$ represent the values of different kink lengths. Here, $a_{i}$ represents the final crack length when the maximum equivalent stress intensity factor reaches the fracture toughness value of 17.6 MPa $\sqrt{\mathrm{m}}$ (which represents the fracture toughness of the $90^{\circ}$ specimens in Somekawa and Mukai [17]). The values of $\Delta k_{e}$ in Equation (6) for different kink lengths are based on the dimensionless geometric function $f_{\mathrm{e}}$ shown in Figure 16. In order to estimate the fatigue lives, the equivalent local stress intensity factor solution for kinked cracks with zero (or near zero) kink length is needed. The analytical local stress intensity factor solutions of He and Hutchinson [18] are expressed as functions of the kink length for small kinked cracks as

$k_{I}+i k_{I I}=\left(c_{R}+i c_{I}\right)\left(K_{1}^{A}+i K_{2}^{A}\right) a^{i \varepsilon}+\left(d_{R}-i d_{I}\right)\left(K_{1}^{A}-i K_{2}^{A}\right) a^{-i \varepsilon}$

where $K_{1}^{A}$ and $K_{2}^{A}$ represent the global stress intensity factors for the main crack obtained from ABAQUS. The detailed finite element model for obtaining the global stress intensity factor solutions is explained in Lai and Pan [14]. Here, $c_{R}, c_{I}, d_{R}$ and $d_{I}$ are the real and imaginary parts of the complex functions $c$ and $d$. Both $c$ and $d$ are complex functions of the Dundur's parameters $\alpha$ and $\beta$ and the kinked angle. The detailed procedure for the selections of the values of $c_{R}, c_{I}, d_{R}$ and $d_{I}$ is explained in Lai and Pan [14]. As shown in Lai and Pan [14], the analytical solutions are in agreement with the solutions from the finite element analyses only when the kink length becomes very small. The grain size of the magnesium sheet ranges from 2 to $15 \mu \mathrm{m}$ with an average grain size of $5 \mu \mathrm{m}$ as reported in Santella et al. [1]. The analytical stress intensity factor solution is $20 \%$ smaller than that obtained from the finite element analysis for the kink length equal to the average grain size of $5 \mu \mathrm{m}$. Therefore, the equivalent local stress intensity factor solution for the kinked length of $5 \mu \mathrm{m}$ from the finite element analysis of Lai and Pan [14] is adopted for the integration of Equation (6) for the range of $a$ from 0 to $5 \mu \mathrm{m}$. 
Since the material constants $C$ and $m$ for the rolled AZ31B-H24 used in this study are not available, they were chosen from those of the AZ31 with a similar grain size. It should be noted that the fatigue crack growth rate varies with the grain size, load ratio, texture and humidity for AZ31. Uematsu et al. [19] studied the fatigue crack growth rate for extruded AZ31 and found the fatigue crack growth rate decreases with the decreasing grain size. Zheng et al. [20] conducted tests to obtain fatigue crack growth rates under different load ratios for extruded AZ31 and found the fatigue crack growth rate increases with the increasing load ratio. Ishihara et al. [21] studied the fatigue crack growth rates for extruded and rolled AZ31 and found a significant texture effect on the fatigue crack growth rate for both extruded and rolled AZ31. Tokaji et al. [22] conducted fatigue tests of rolled AZ31 under dry and humid air conditions and found an order of magnitude of difference in fatigue crack growth rate. The grain size of the rolled AZ31 in this investigation is close to that of the extruded AZ31 of Ishihara et al. [23]. Therefore, the material constants $C$ and $m$ for crack growth rate reported in Ishihara et al. [23] were selected to estimate the fatigue lives. Since the humidity measured in the laboratory is between the dry air and the laboratory air conditions defined in Tokaji et al. [22], the material constants $C$ and $m$ reported in Tokaji et al. [22] for the dry and laboratory air conditions were also used to estimate the fatigue lives to show the humidity effects. It should be mentioned that the grain size of the rolled AZ31 of Tokaji et al. [22] is much larger than that of the rolled AZ31 in this investigation.

The values of $C$ and $m$ are $4 \times 10^{-7} \mathrm{~mm} / \mathrm{cycle} /(\mathrm{MPa} \sqrt{\mathrm{m}})^{m}$ and 2.7 for the laboratory air condition reported in Ishihara et al. [23], $1.36 \times 10^{-7} \mathrm{~mm} / \mathrm{cycle} /(\mathrm{MPa} \sqrt{\mathrm{m}})^{m}$ and 2.8 for the dry air condition and $1.86 \times 10^{-6}$ $\mathrm{mm} / \mathrm{cycle} /(\mathrm{MPa} \sqrt{\mathrm{m}})^{m}$ and 2.8 for the laboratory air condition, respectively, reported in Tokaji et al. [22]. The estimated fatigue lives for the adhesive-bonded/weld-bonded lap-shear specimens failed in the kinked fatigue crack failure mode are shown as the different lines in Figure 4. As shown in the figure, the estimated fatigue lives based on the material constants $C$ and $m$ for the AZ31 with the similar grain size under the laboratory air condition in Ishihara et al. [23] are lower than the experimental results. The estimated fatigue lives based on the material constants for the AZ31 with a much larger grain size under the laboratory air condition in Tokaji et al. [22] are much lower than the experimental fatigue lives. The estimated fatigue lives based on the material constants for the AZ31 with a much larger grain size under the dry air condition in Tokaji et al. [22] are much longer and close to the experimental results. When the trend of the estimated fatigue lives based on the material constants in Tokaji et al. 


\section{Conclusion}

Failure modes and fatigue behaviors of ultrasonic spot welds, adhesive-bonded joint, and ultrasonic spot welds with adhesive in lap-shear specimens of magnesium AZ31B-H24 and hot-dipped-galvanized mild steel sheets were investigated. The ultrasonic spot weld appears not to provide extra strength to the weld-bonded lap-shear specimen under quasi-static and cyclic loading conditions due to the poor weld quality from the residual adhesive at the interface. The quasi-static and fatigue strengths of adhesive-bonded and weld-bonded lap-shear specimens appear to be the same.

Optical micrographs of the joints and SEM images of the fracture surfaces after the tests were examined to understand the failure modes of the joints. For the ultrasonic spot welded lap-shear specimens, the optical micrographs indicate that the failure mode changes from the partial nugget pullout mode under quasi-static loading conditions to the kinked crack failure mode under cyclic loading conditions. For the adhesive-bonded lap-shear specimens, the optical micrographs indicate that the failure mode changes from the near interface cohesive failure mode through the adhesive under quasi-static and low-cycle loading conditions to the kinked crack growth mode through the magnesium sheet under high-cycle loading conditions. For the weld-bonded lap-shear specimens, the optical micrographs indicate that the failure mode changes from the near interface cohesive failure mode through the adhesive and the interfacial failure mode through the ultrasonic spot weld under quasi-static and low-cycle loading conditions to the kinked crack failure mode through the magnesium sheet under high-cycle loading conditions. Finally, the fatigue lives for the adhesive-bonded and weld-bonded specimens failed in the kinked crack growth mode were estimated under high-cycle loading conditions. The estimated fatigue lives are lower than the experimental results. However, the general trend of the estimated fatigue lives agrees with that of the experimental results. 


\section{Acknowledgments}

This research was sponsored by the U.S. Department of Energy, Assistant Secretary for Energy Efficiency and Renewable Energy, Office of Vehicle Technologies, as part of the Lightweight Materials Program. Helpful discussions with Drs. Tsung-Yu Pan, Michael Santella, and Zhili Feng of Oak Ridge National Laboratory and Dr. Teresa Rinker of General Motors are greatly appreciated.

\section{References}

[1] Santella M, Franklin T, Pan J, Pan T-Y, Brown E. Ultrasonic spot welding of AZ31B to galvanized mild steel. SAE International Journal of Materials and Manufacturing. 2010;3:652-7.

[2] Pan T-Y. Friction stir spot welding (FSSW) - a literature review. SAE technical paper no. 2007-01-1702. Warrendale, PA: Society of Automotive Engineers; 2007.

[3] Gendo T, Nishiguchi K, Asakawa M, Tanioka S. Spot friction welding of aluminum to steel. SAE technical paper no. 2007-01-1703. Warrendale, PA: Society of Automotive Engineers; 2007.

[4] Liyanage T, Kilbourne J, Gerlich AP, North TH. Joint formation in dissimilar Al alloy/steel and Mg alloy/steel friction stir spot welds. Science and Technology of Welding and Joining. 2009;14:500-8.

[5] Hetrick E, Jahn R, Reatherford L. Ultrasonic spot welding: a new tool for aluminum joining. Welding Journal. 2005;84:26-30.

[6] Jahn R, Cooper R, Wilkosz D. The effect of anvil geometry and welding energy on microstructures in ultrasonic spot welds of AA6111-T4. Metallurgical and Materials Transactions A: Physical Metallurgy and Materials Science. 2007;38:570-83.

[7] Wright NW, Robson JD, Prangnell PB. Effects of thickness combinations on joint properties and process windows in ultrasonic metal welding. SAE technical paper no. 2009-01-0027. Warrendale, PA: Society of Automotive Engineers; 2009.

[8] Watanabe A, Watanabe T, Sasaki T, University N. Ultrasonic welding mild steel sheet to al-mg alloy sheet. Advanced Materials Research. 2010;89-91:627-32.

[9] Shakil M, Tariq NH, Ahmad M, Choudhary MA, Akhter JI, Babu SS. Effect of ultrasonic welding parameters on microstructure and mechanical properties of dissimilar joints. Materials \& Design. 2014;55:263-73.

[10] Matsuoka S, Imai H. Direct welding of different metals used ultrasonic vibration. Journal of Materials Processing Technology. 2009;209:954-60.

[11] Franklin T, Pan J, Santella M, Pan T-Y. Fatigue behavior of dissimilar ultrasonic spot welds in lap-shear specimens of magnesium and steel sheets. SAE International Journal of Materials and Manufacturing. 2011;4:581-8.

[12] Carboni M, Moroni F. Tensile-shear fatigue behavior of aluminum and magnesium lap-joints obtained by ultrasonic welding and adhesive bonding. Procedia Engineering. 2011;10:3561-6.

[13] Heyes P, Björkman G, Blows A, Mumford T, Briskham P. A fracture mechanics approach to durability calculations for adhesive joints. SAE International Journal of Materials and Manufacturing. 2012;5:215-25. 
[14] Lai W-J, Pan J. Stress intensity factor solutions for adhesive-bonded lap-shear specimens of magnesium and steel sheets with and without kinked cracks for fatigue life estimations. Engineering Fracture Mechanics.

2014;131:454-70.

[15] Franklin T. Fatigue behavior and life estimation for dissimilar ultrasonic welds in lap-shear specimens of magnesium and galvanized steel sheets [dissertation]. Ann Arbor (MI): University of Michigan; 2013.

[16] Broek D. Elementary engineering fracture mechanics. 4th ed. Martinus Nijhoff Publisher; 1986.

[17] Somekawa H, Mukai T. Fracture toughness in a rolled AZ31 magnesium alloy. Journal of Alloys and Compounds. 2006;417:209-13.

[18] He M-Y, Hutchinson JW. Kinking of a crack out of an interface. Journal of Applied Mechanics. 1989;56:270-8.

[19] Uematsu Y, Tokaji K, Kamakura M, Uchida K, Shibata H, Bekku N. Effect of extrusion conditions on grain refinement and fatigue behaviour in magnesium alloys. Materials Science and Engineering: A. 2006;434:131-40.

[20] Zheng S, Yu Q, Jiang Y. An experimental study of fatigue crack propagation in extruded AZ31B magnesium alloy. International Journal of Fatigue. 2013;47:174-83.

[21] Ishihara S, Taneguchi S, Shibata H, Goshima T, Saiki A. Anisotropy of the fatigue behavior of extruded and rolled magnesium alloys. International Journal of Fatigue. 2013;50:94-100.

[22] Tokaji K, Nakajima M, Uematsu Y. Fatigue crack propagation and fracture mechanisms of wrought magnesium alloys in different environments. International Journal of Fatigue. 2009;31:1137-43.

[23] Ishihara S, McEvily AJ, Sato M, Taniguchi K, Goshima T. The effect of load ratio on fatigue life and crack propagation behavior of an extruded magnesium alloy. International Journal of Fatigue. 2009;31:1788-94. 
Table 1. Elastic moduli, yield stresses, and tensile strengths of the magnesium and steel sheets tested under quasistatic loading conditions at a displacement rate of $5 \mathrm{~mm} / \mathrm{min}$.

\begin{tabular}{|c|c|c|c|}
\hline & Elastic modulus (GPa) & Yield stress (MPa) & Tensile strength (MPa) \\
\hline AZ31 & 45 & 260 & 318 \\
\hline HDG mild steel & 210 & 145 & 293 \\
\hline
\end{tabular}

Table 2. Failure loads of the lap-shear specimens tested under quasi-static loading conditions at a displacement rate of $5 \mathrm{~mm} / \mathrm{min}$.

\begin{tabular}{|c|c|}
\hline & Failure load (N) \\
\hline USW & $4,040 \pm 13$ \\
\hline Adhesive-bonded & $6,524 \pm 65$ \\
\hline Weld-bonded & $6,403 \pm 61$ \\
\hline
\end{tabular}




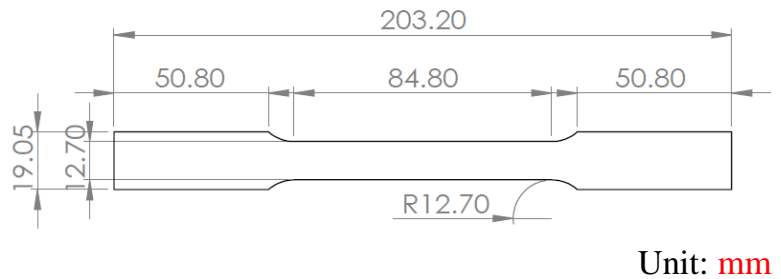

(a)

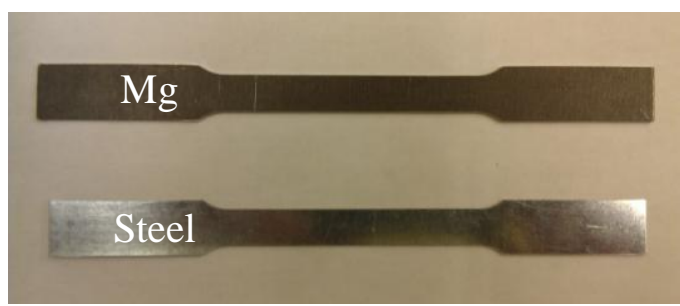

(b)

Figure 1. (a) A schematic of a tensile specimen with the dimensions (ASTM E8/E8M-11) and (b) a picture of the tensile specimens of the magnesium and steel sheets with the thicknesses of $1.6 \mathrm{~mm}$ and $0.8 \mathrm{~mm}$, respectively, from the top to the bottom.

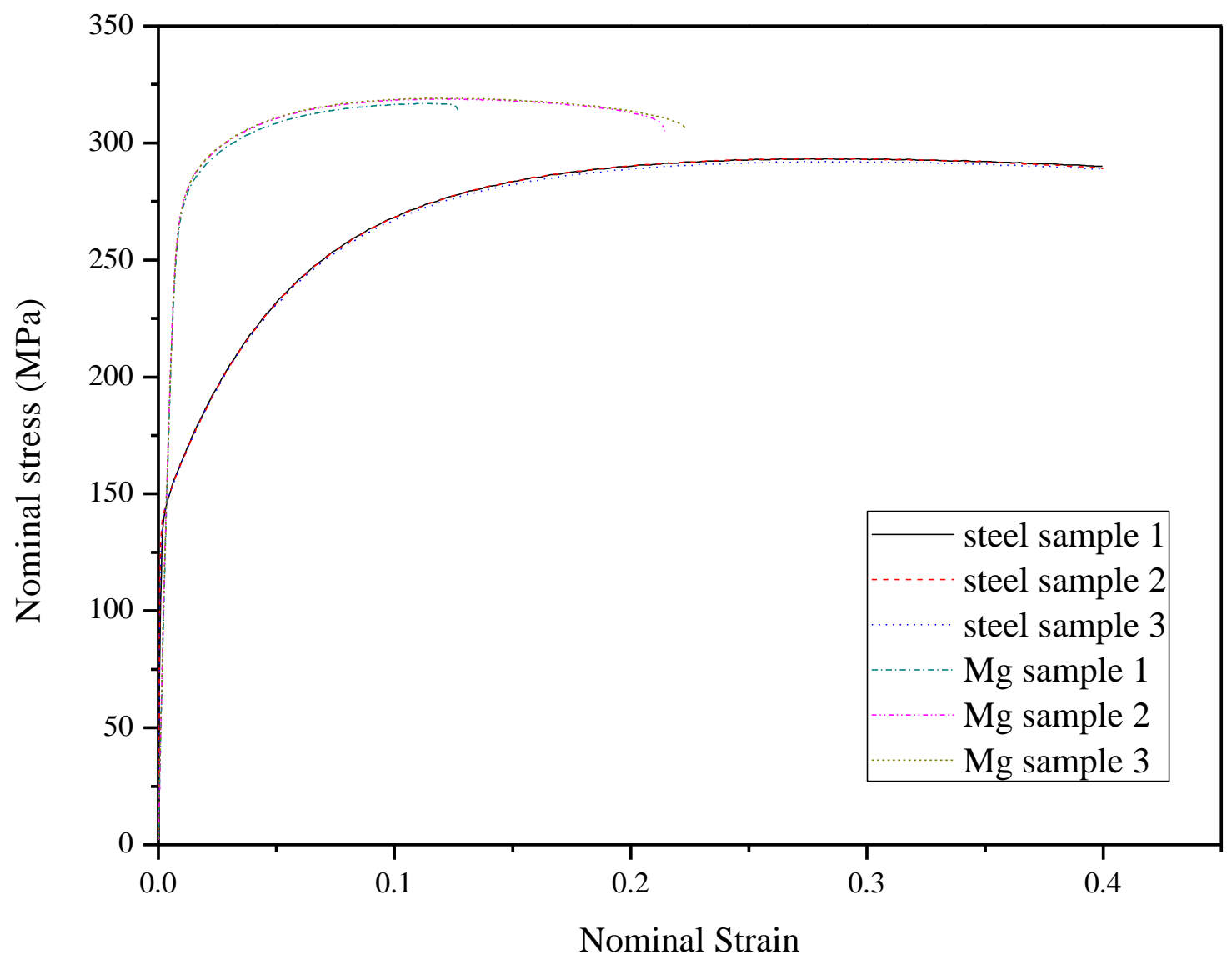

Figure 2. Nominal tensile stress-strain curves of the magnesium and steel sheets tested at a displacement rate of 2.54 $\mathrm{mm} / \mathrm{min}$ (nominal strain rate of $0.00085 \mathrm{~s}^{-1}$ ). 

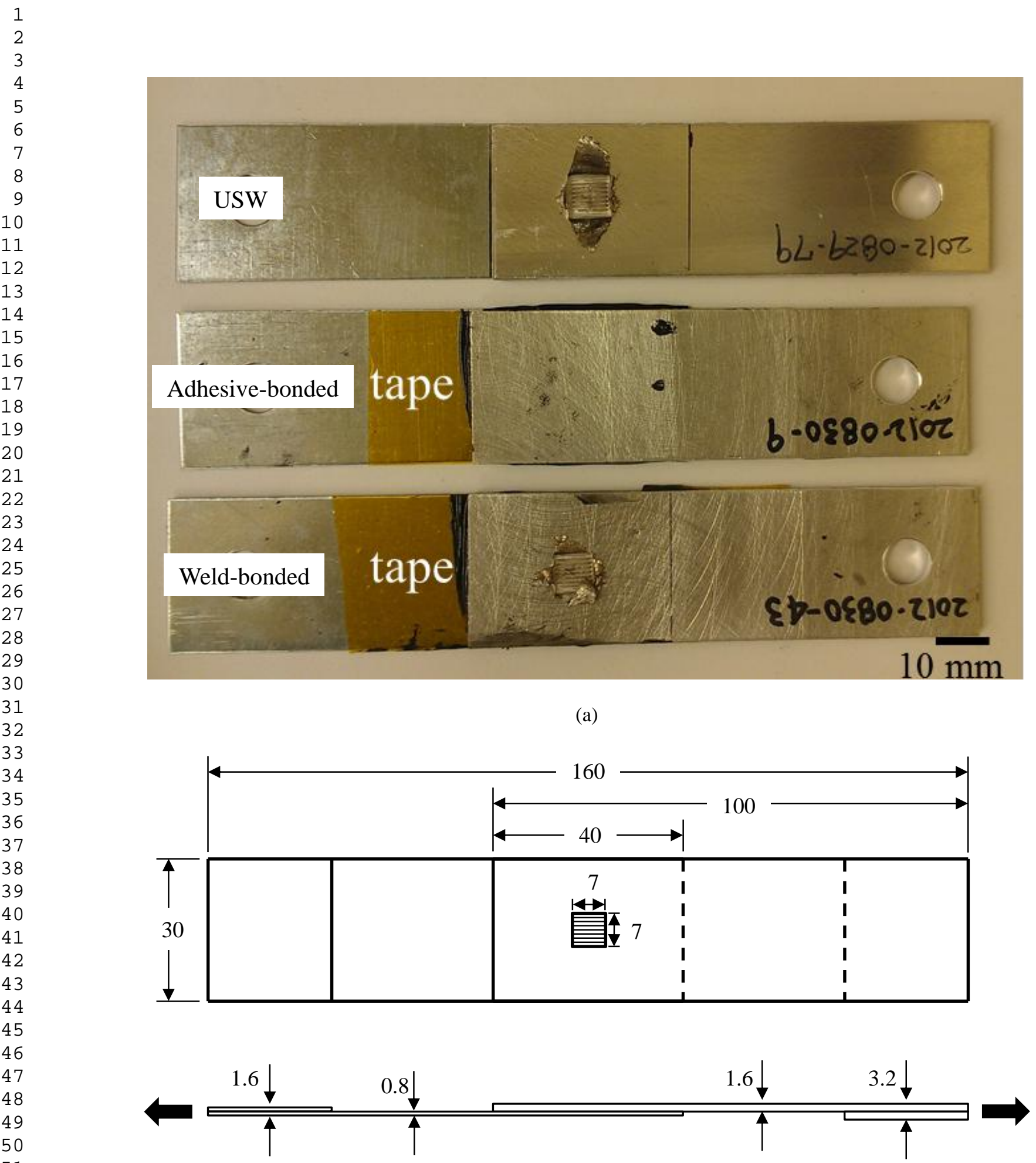

Unit: mm

(b) 

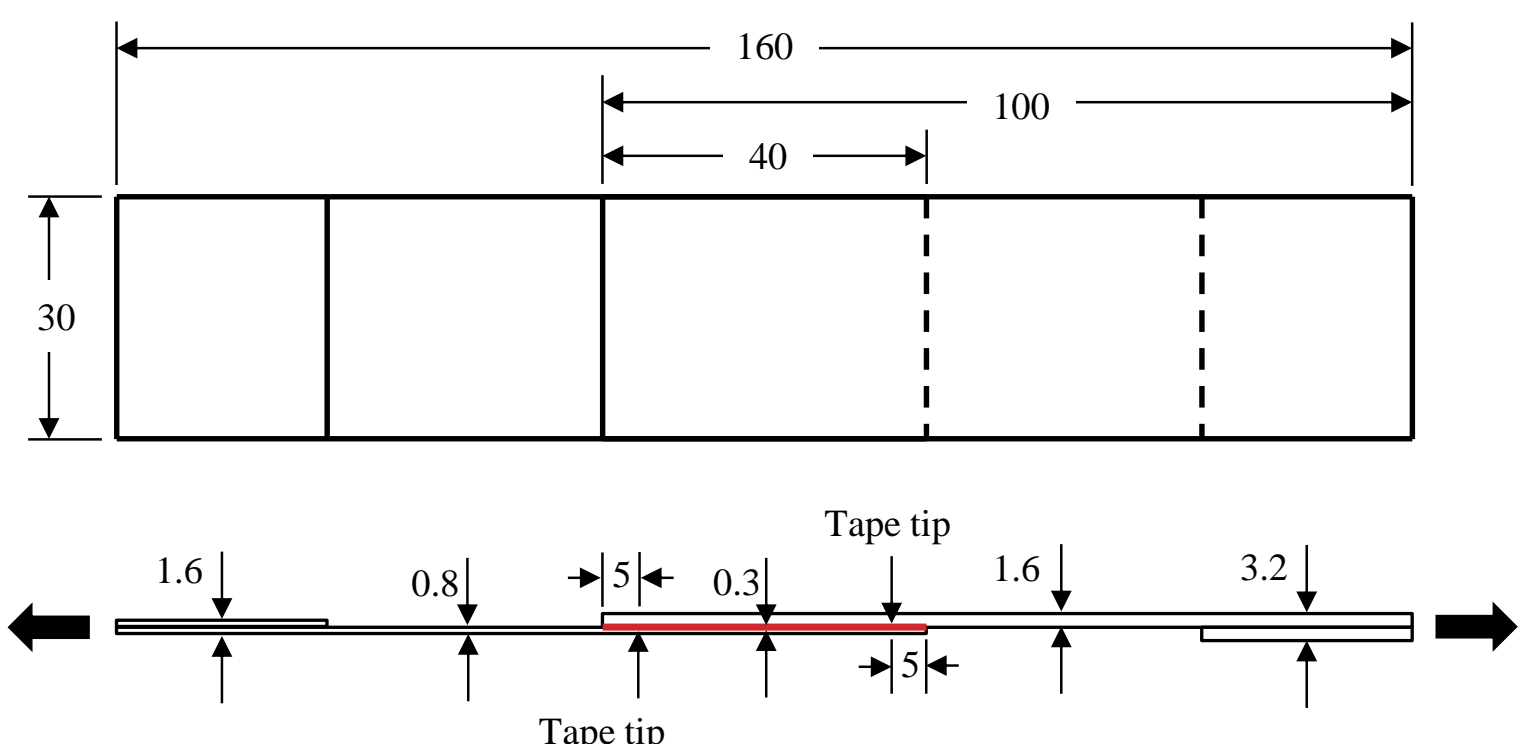

Unit: mm

(c)
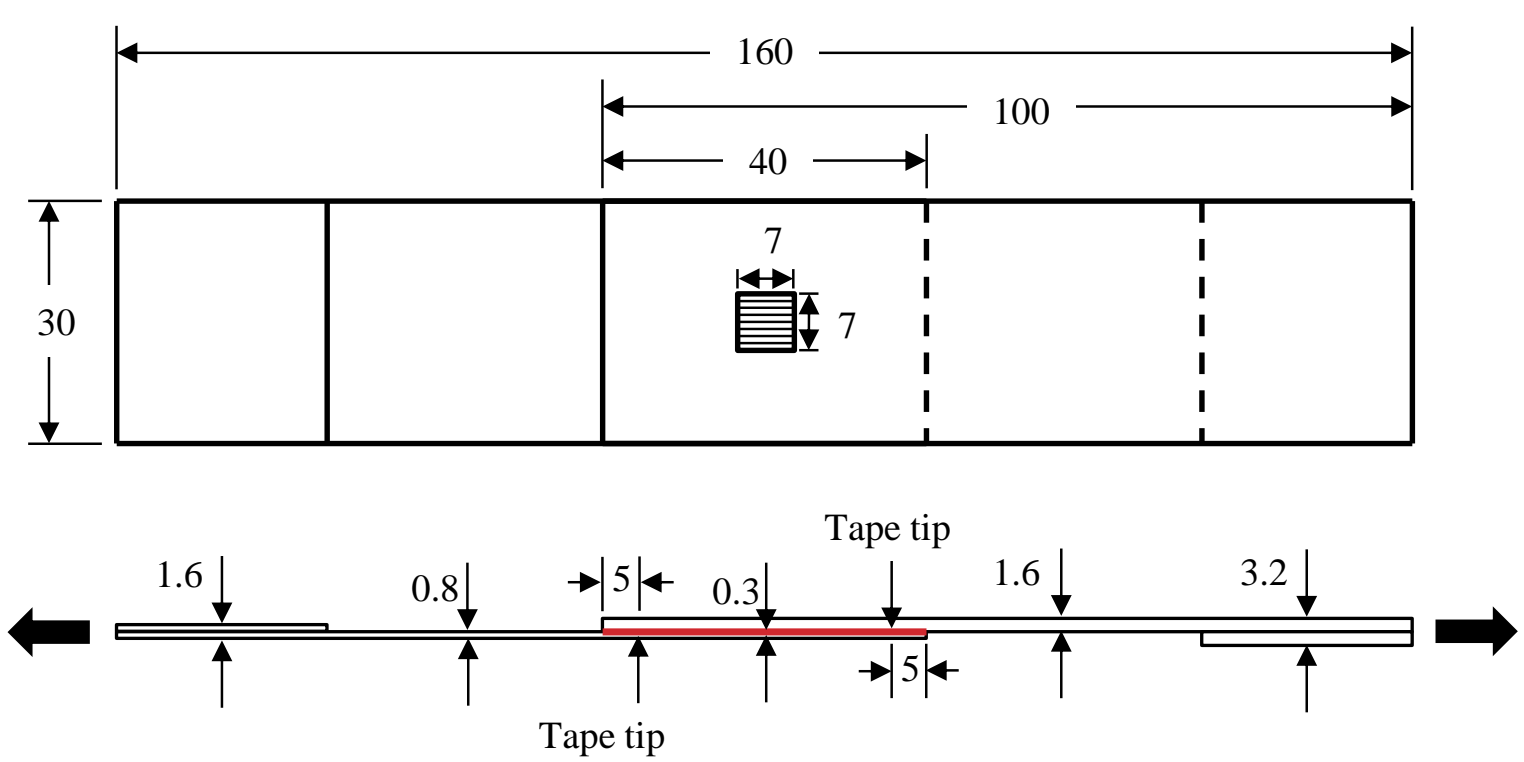

Unit: mm

(d)

Figure 3. (a) A top view of USW, adhesive-bonded, and weld-bonded lap-shear specimens, from the top to the bottom. (b)-(d) Schematics of the top and the side views of the USW, adhesive-bonded, and weld-bonded specimens with the loading directions shown by the arrows. The red lines represent the adhesive. 
Figure 4. The experimental results and the fatigue life estimations based on a kinked fatigue crack growth model for the adhesive-bonded and weld-bonded lap-shear specimens using the material constants for different crack growth rates for different AZ31's under different testing conditions.

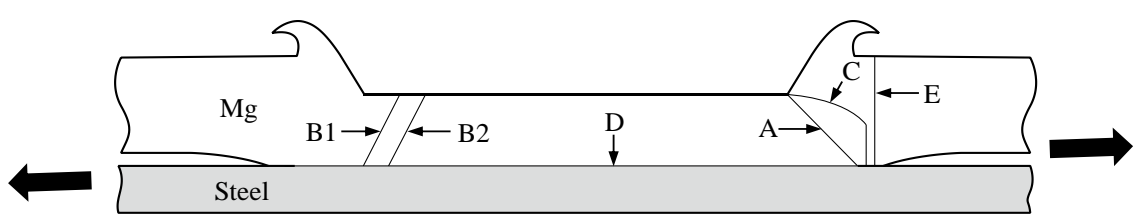

(a)

\begin{tabular}{|c|c|}
\hline & Failure mode \\
\hline Quasi-static (QS) & $\mathrm{A} \rightarrow \mathrm{B} 1$, partial nugget pullout \\
\hline Low-cycle (LC) & $\mathrm{C} \rightarrow \mathrm{B} 2$, kinked crack and partial nugget pullout \\
\hline High-cycle high-load (HC-HL) & $\mathrm{E} \rightarrow \mathrm{D}$, kinked crack and interfacial failure \\
\hline High-cycle low-load (HC-LL) & E, kinked crack and transverse crack \\
\hline
\end{tabular}

(b)

Figure 5. (a) A schematic of the cross section near the ultrasonic spot weld and (b) a summary of the failure modes of the ultrasonic spot weld. 
1

2

3

4

5

6

7

8

9

10

11

12

13

14

15

16

17

18

19

20

21

22

23

24

25

26

27

28

29

30

31

32

33

34

35

36

37

38

39

40

41

42

43

44

45

46

47

48

49

50

51

52

53

54

55

56

57

58

59

60

61

62

63

64

65

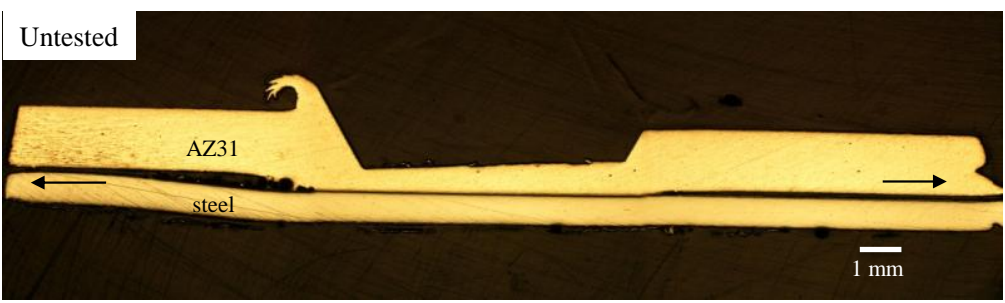

6(a)

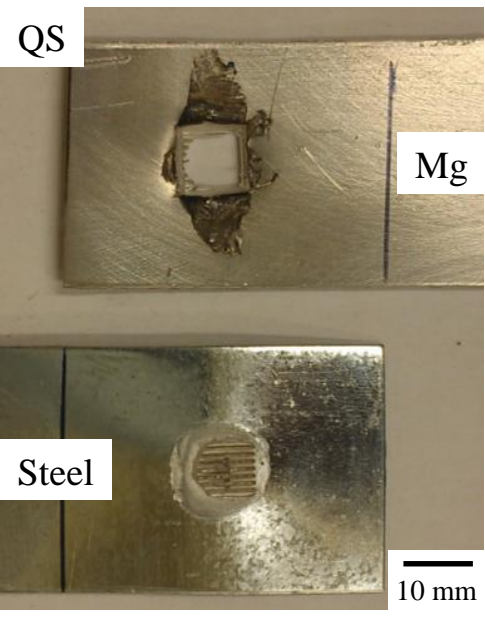

6(b)

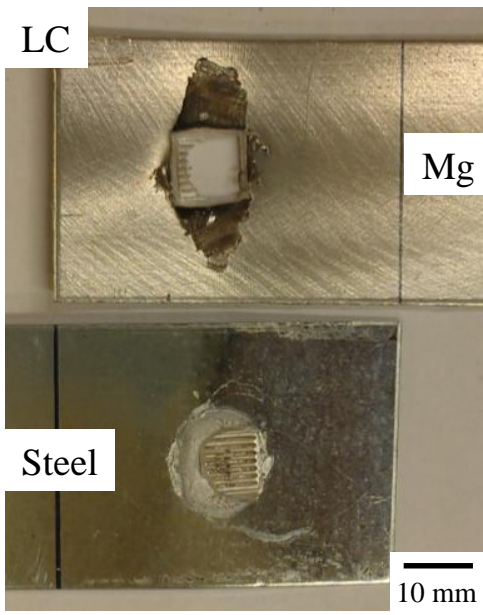

6(d)

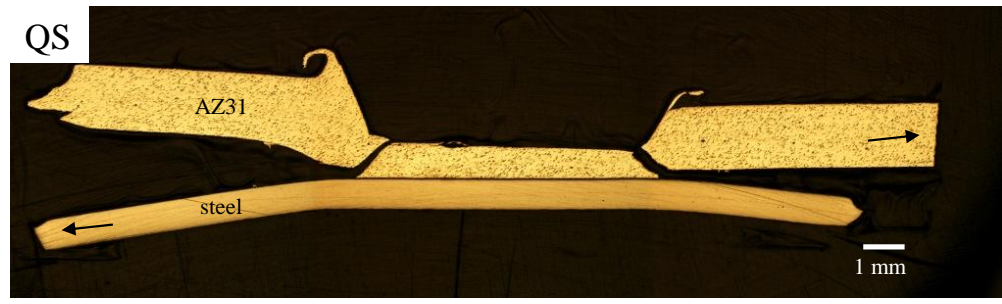

6(c)

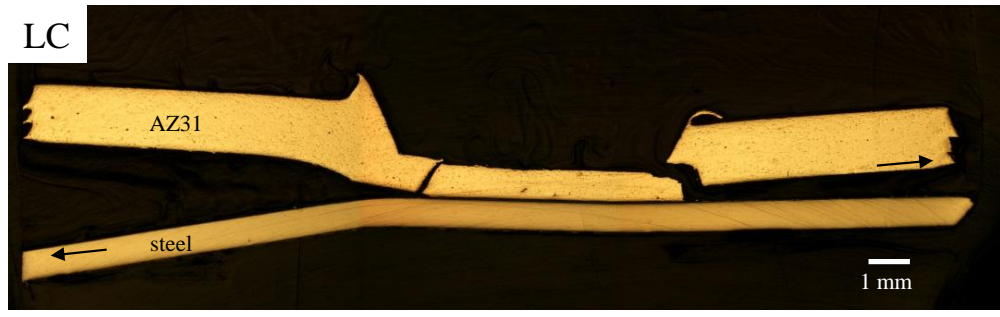

6(e) 


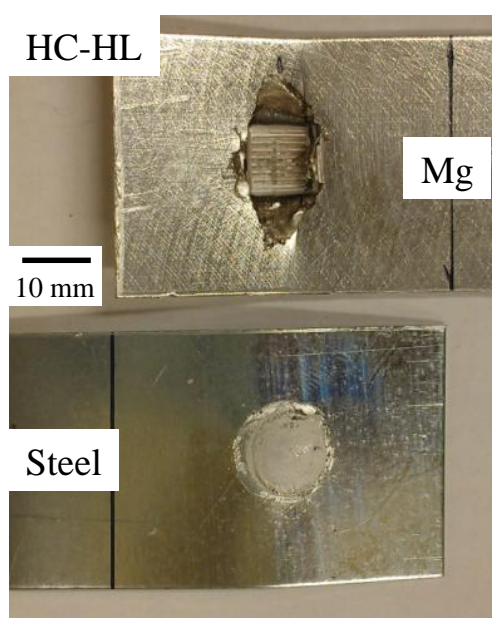

6(f)

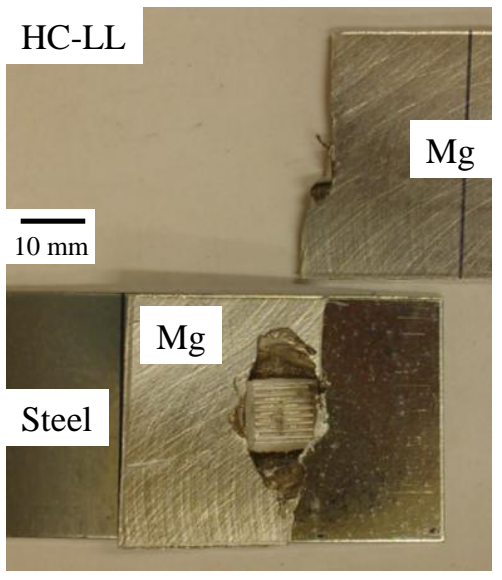

6(h)

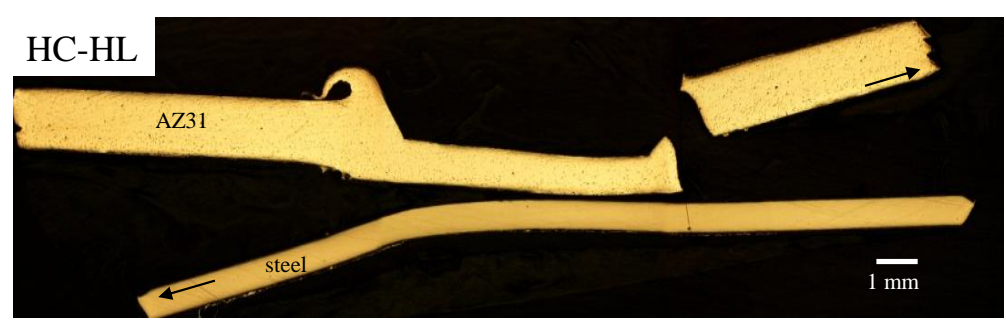

$6(\mathrm{~g})$

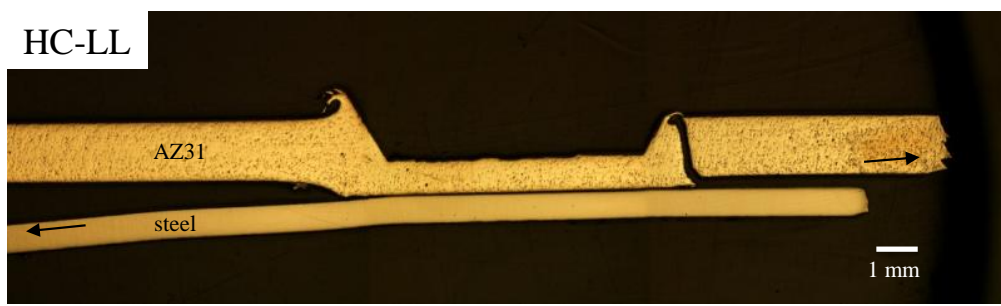

6(i)

Figure 6. (a) A micrograph of the symmetry cross section near the weld in an untested USW lap-shear specimen. Images near the failed welds and the corresponding symmetry cross sections in the USW lap-shear specimens (b, c) under quasi-static loading condition, (d, e) under low-cycle loading conditions, (f, g) under high-cycle high-load loading conditions, and (h, i) under high-cycle low-load loading conditions. The arrows indicate the loading directions. 


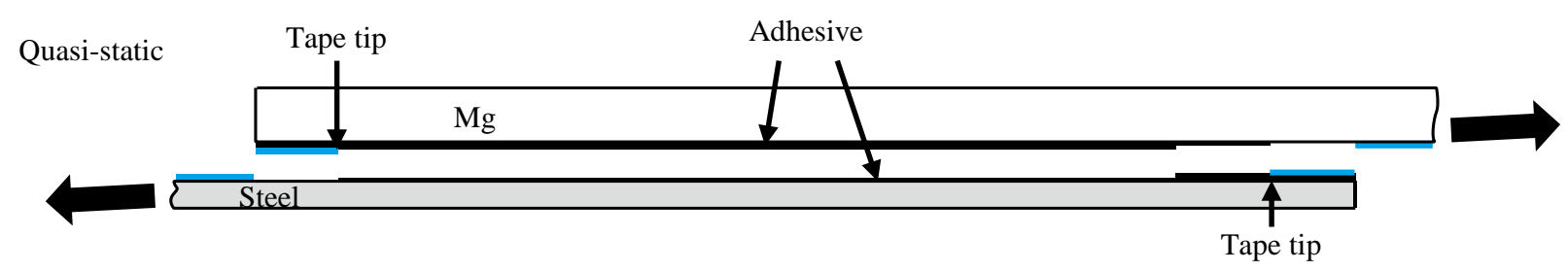

(a)

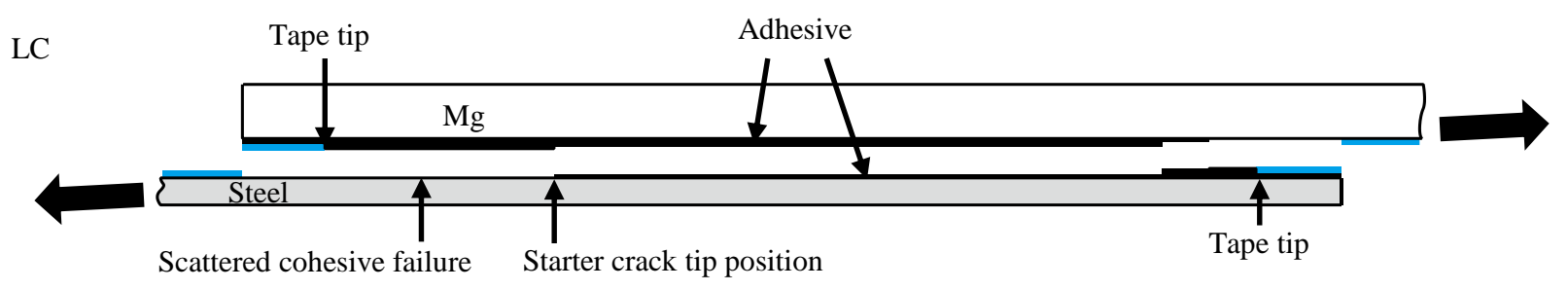

(b)

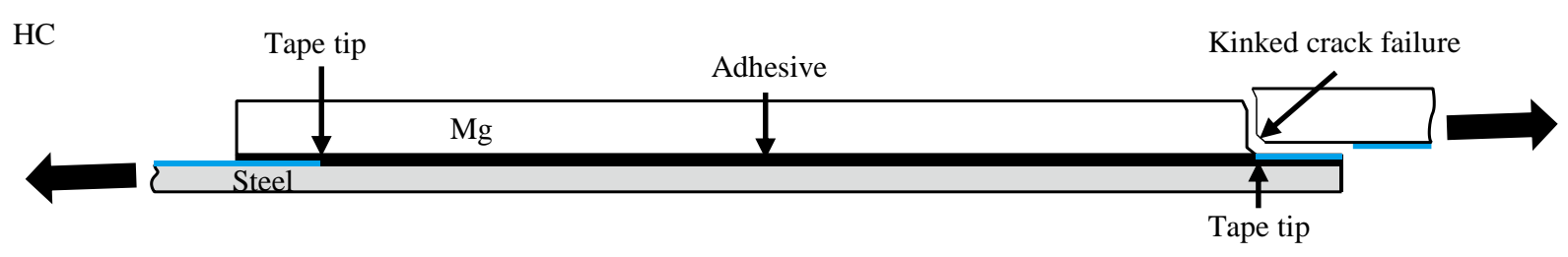

(c)

Figure 7. Schematics of the failure modes under (a) quasi static loading conditions, (b) low-cycle loading conditions and (c) high-cycle loading conditions for adhesive-bonded lap-shear specimens. The blue lines indicate the tapes. 


\section{Untested}

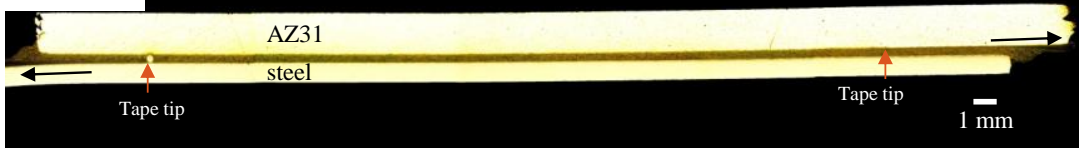

8(a)
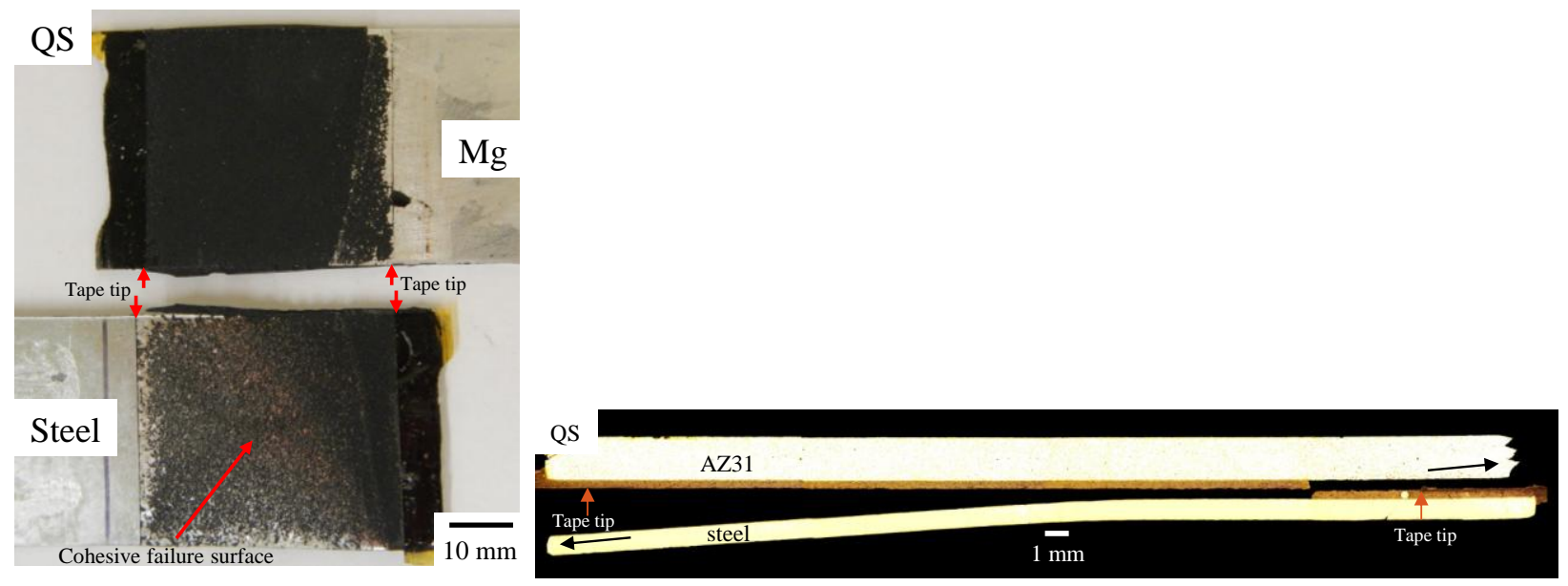

8(b)

8(c)

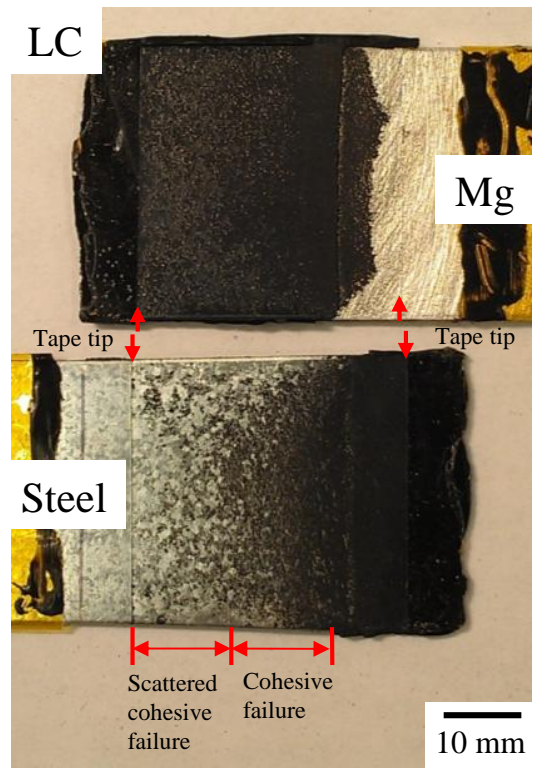

8(d)

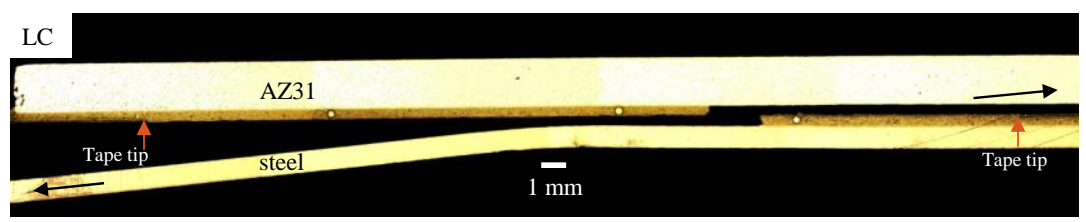

8(e) 


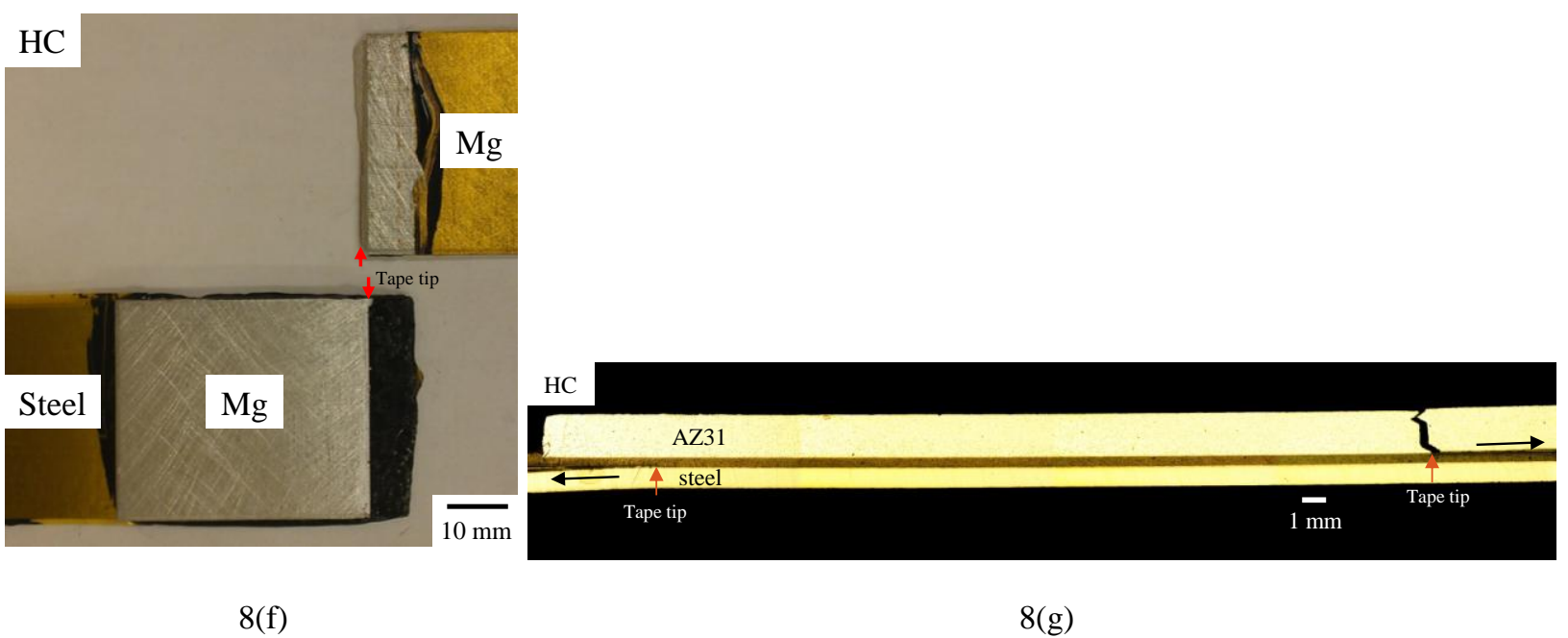

Figure 8. (a) A micrograph of the symmetry cross section near the joint in an untested adhesive-bonded lap-shear specimen. Images near the failed joints and the corresponding symmetry cross sections of the joints in the adhesivebonded lap-shear specimens (b, c) under quasi-static loading condition, $(\mathrm{d}, \mathrm{e})$ under low-cycle loading conditions, and (f, g) under high-cycle loading conditions. The arrows indicate the loading directions. 
Figure 9. Fracture surfaces of the upper right magnesium sheets of failed adhesive-bonded lap-shear specimens under load ranges of (a) 4,630 N, (b) 4,080 N, (c) 3,480 N, and (d) 2,900 N. The red arrow pairs indicate the $30^{\circ}$ kinked cracks and the white arrow pairs indicate the $90^{\circ}$ cracks.

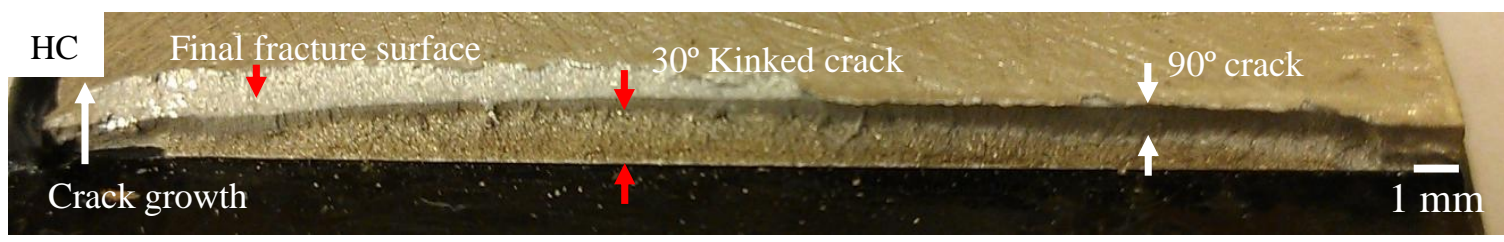

(d)

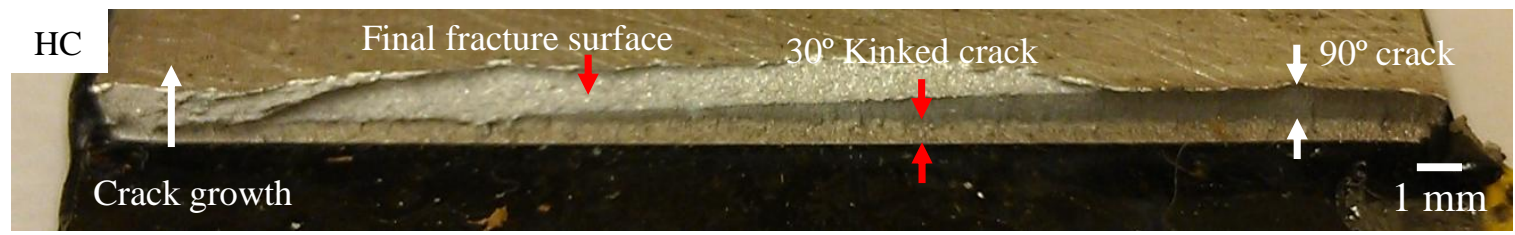

(b)

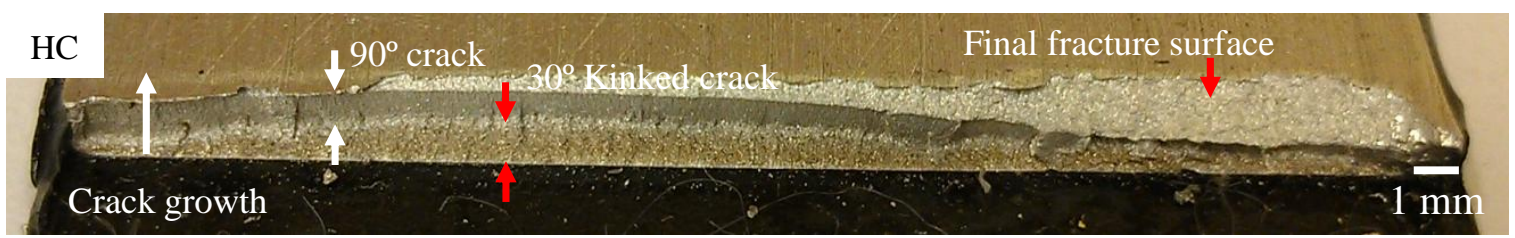

(c) 


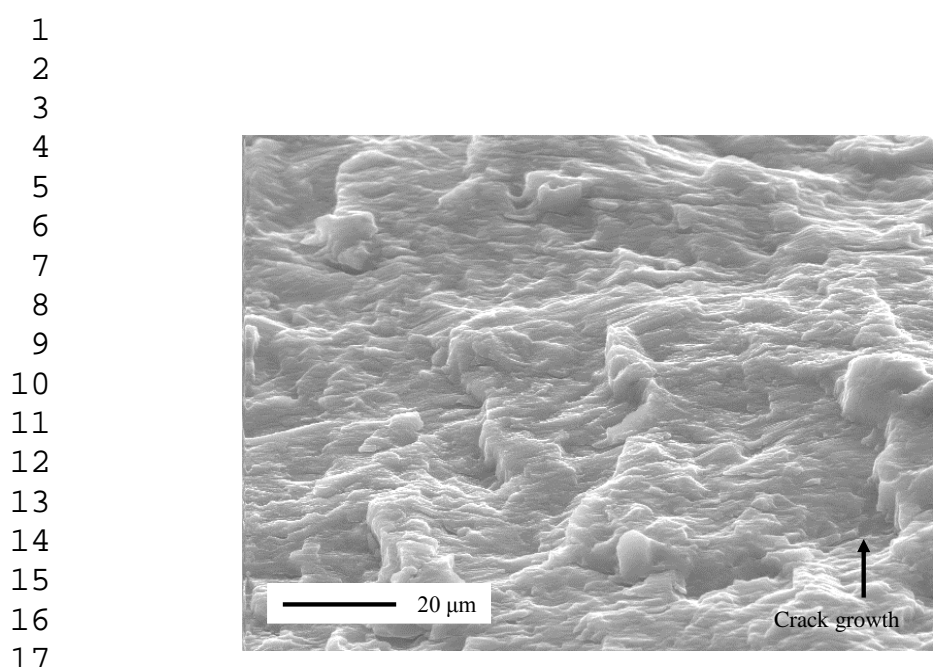

17

19

20

21

22

23

24

25

26

27

28

29

30

31

32

33

34

35

36

37

38

39

40

41

42

43

44

45

46

47

48

49

50

51

52

53

54

55

56

57

58

59

60

61

62

63

64

65 surface of a failed specimen under cyclic loading conditions.

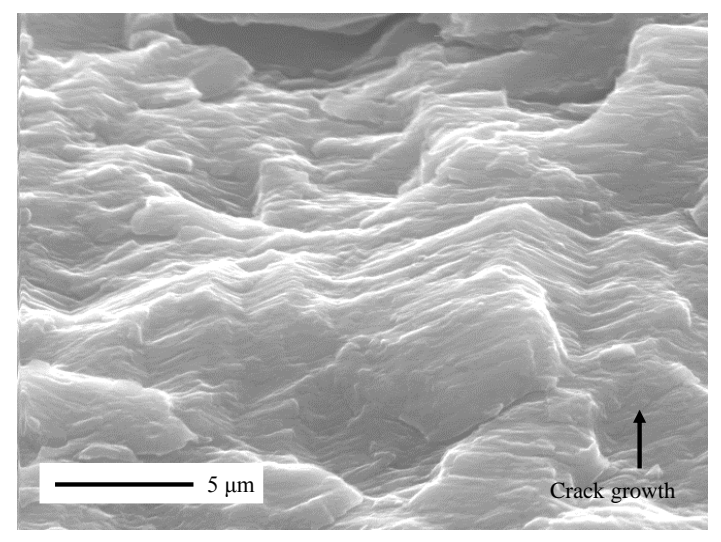

10(b)

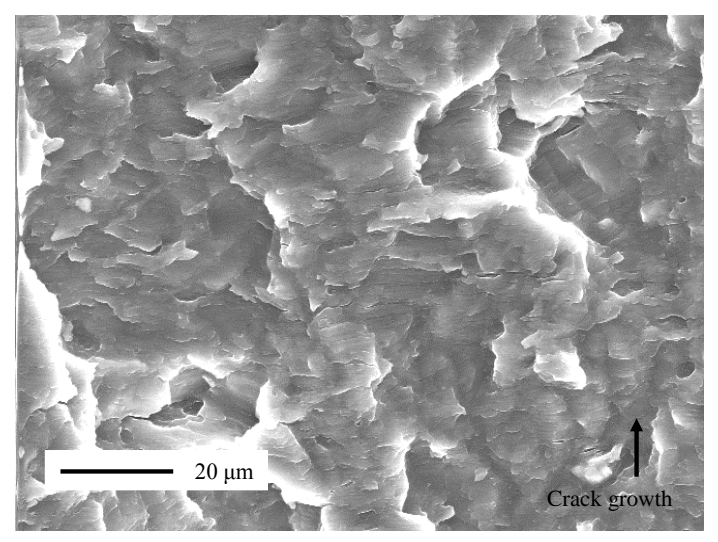

10(c)

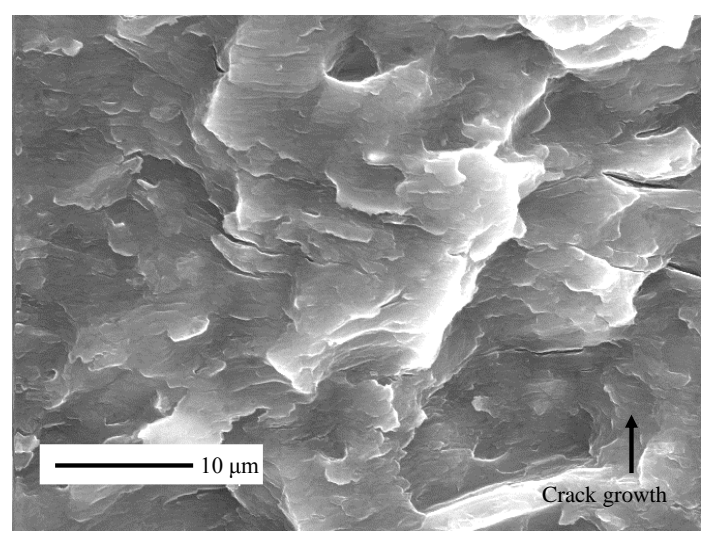

$10(d)$

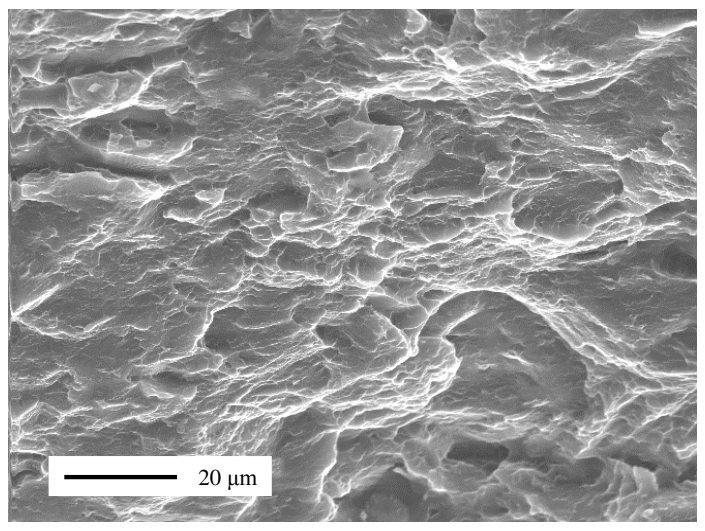

$10(\mathrm{e})$

Figure 10. SEM images of (a, b) the $30^{\circ}$ kinked crack surface, (c, d) the $90^{\circ}$ crack surface, and (e) the final fracture 
Figure 11. Plastic deformation patterns of the steel sheets along the crack fronts (a) in the failed and partially failed specimens under quasi-static loading conditions and (b) in the failed and partially failed specimens under low-cycle loading conditions.

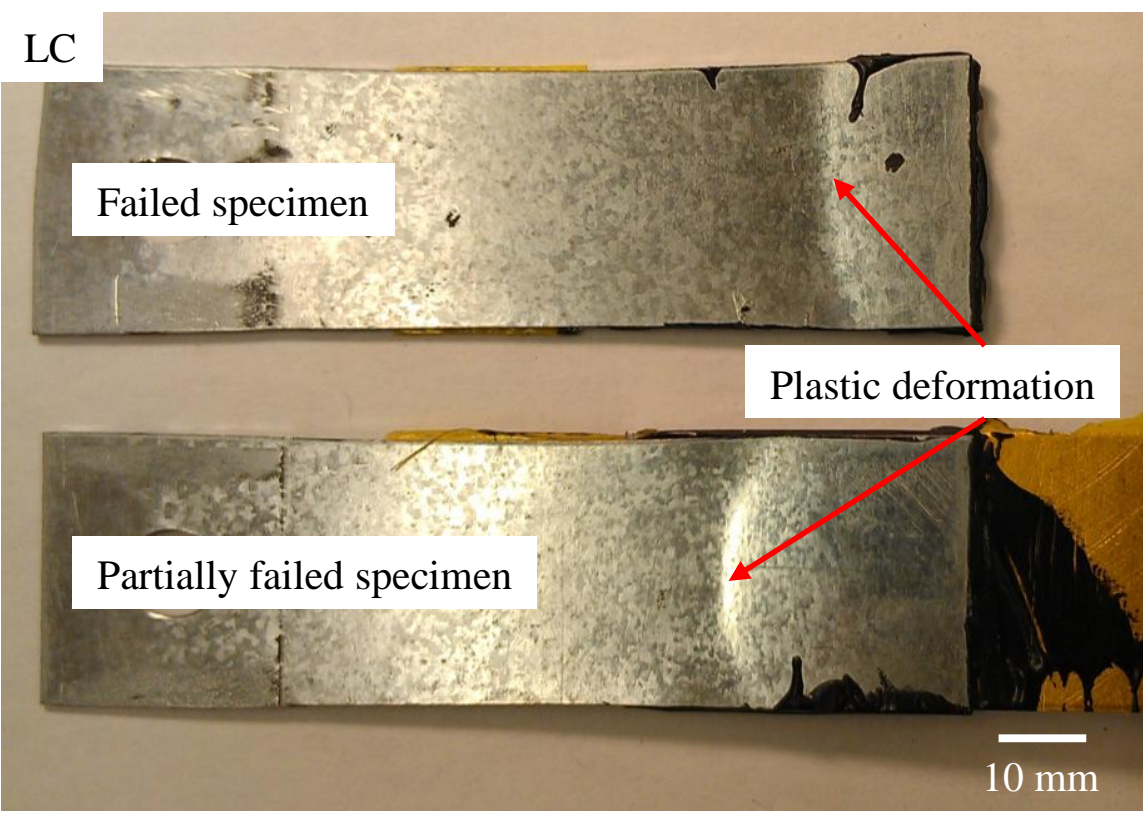

(b)

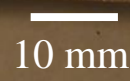

(a) 


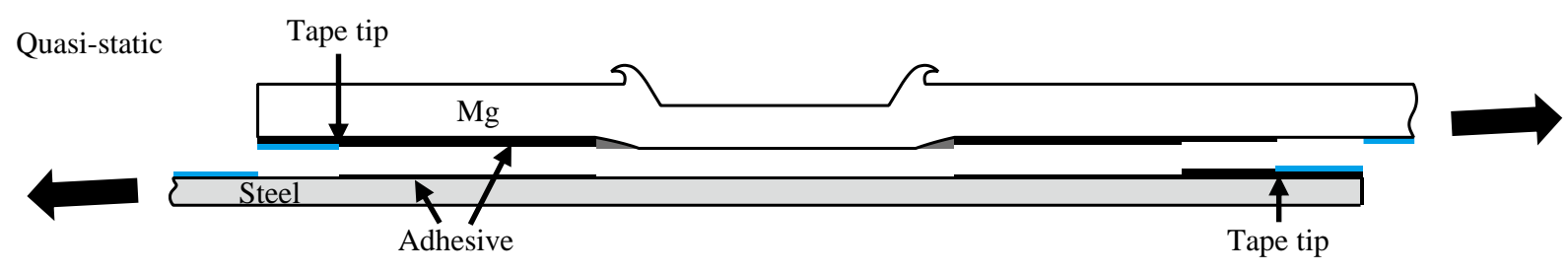

(a)

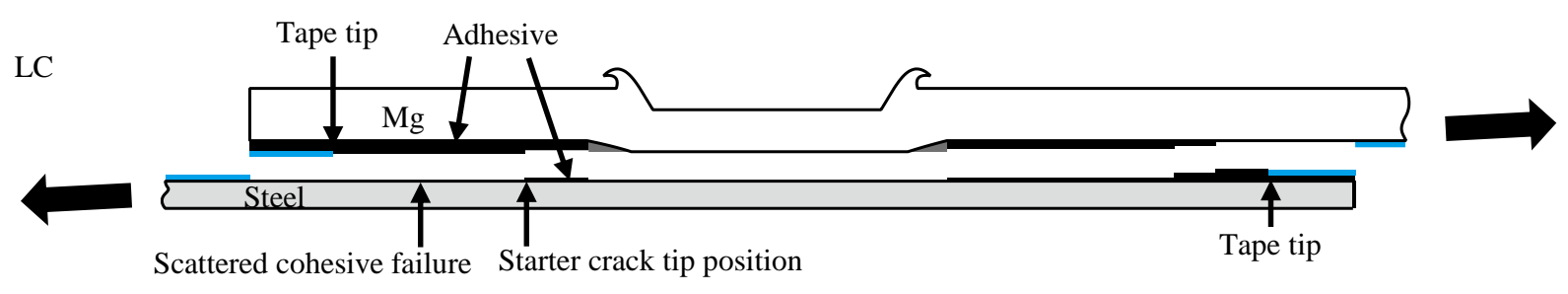

(b)

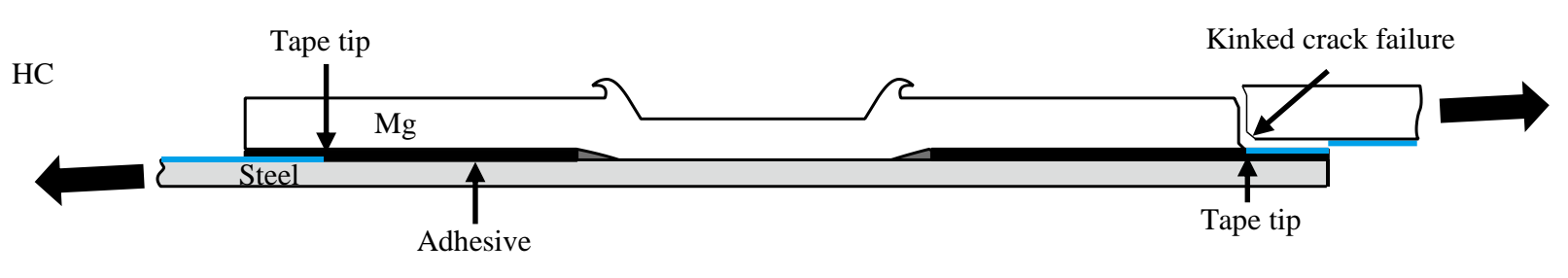

(c)

Figure 12. Schematics of the failure modes under (a) quasi-static loading conditions, (b) low-cycle loading conditions and (c) high-cycle loading conditions for the weld-bonded lap-shear specimens. The blue lines indicate the tapes. 


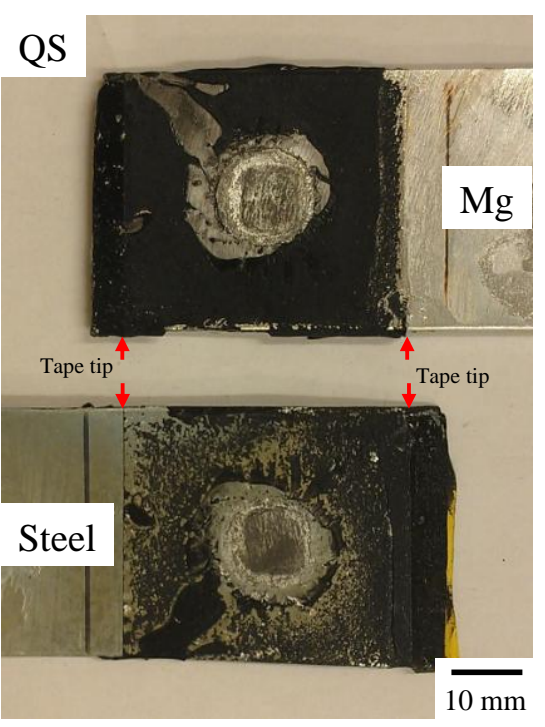
QS

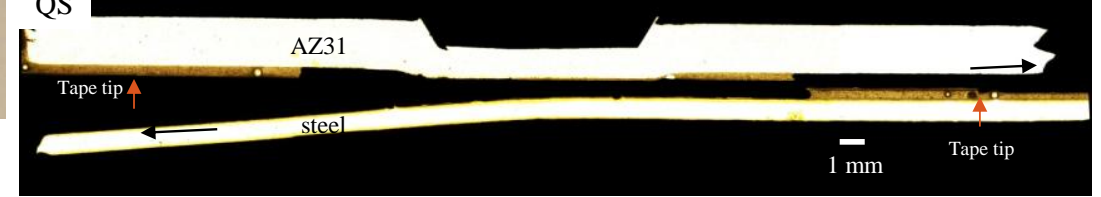

13(b)

13(c)

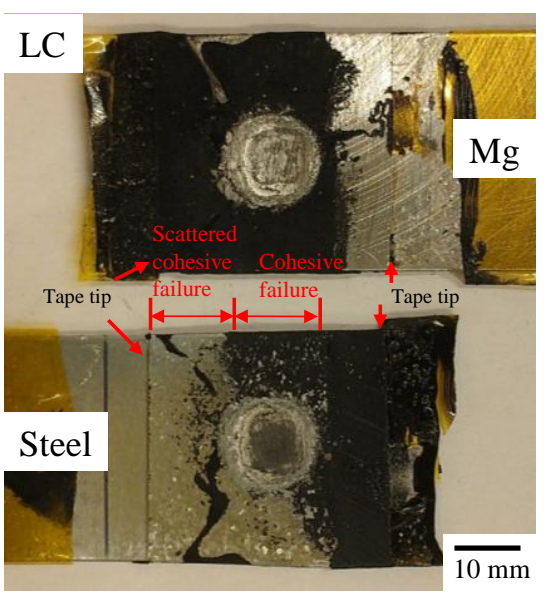

13(a) 


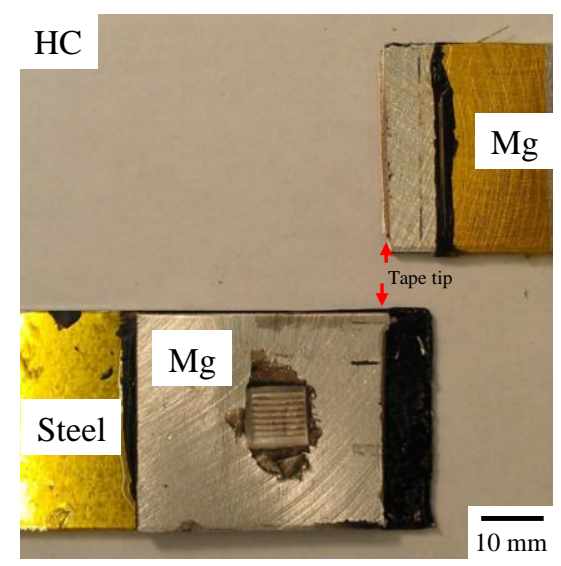

$13(\mathrm{f})$

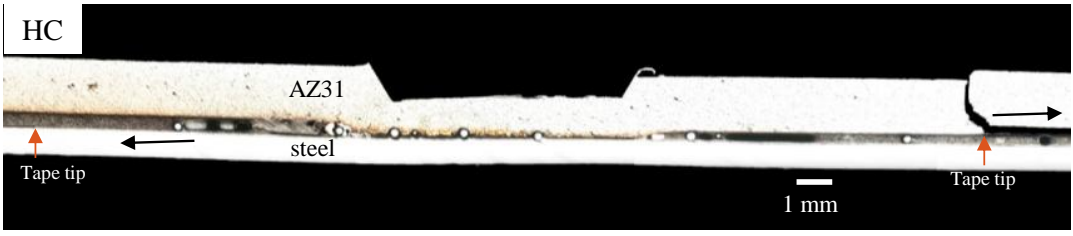

$13(\mathrm{~g})$

Figure 13. (a) A micrograph of the symmetry cross section near the joint in an untested weld-bonded lap-shear specimen. Images near the failed joints and the corresponding symmetry cross sections of the joints in the weldbonded lap-shear specimens (b, c) under quasi-static loading conditions, (d, e) under low-cycle loading conditions, and (f, g) under high-cycle loading conditions. The arrows indicate the loading directions. 


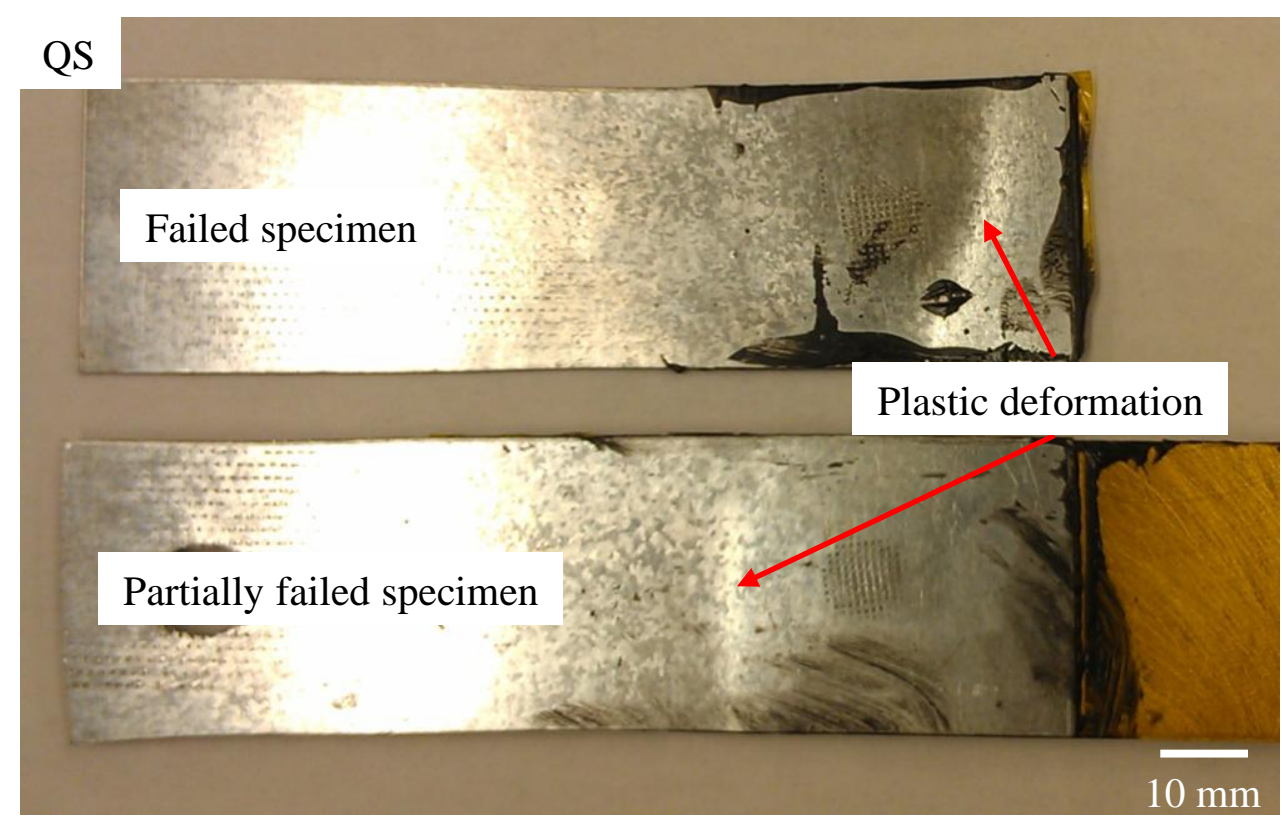

(a)

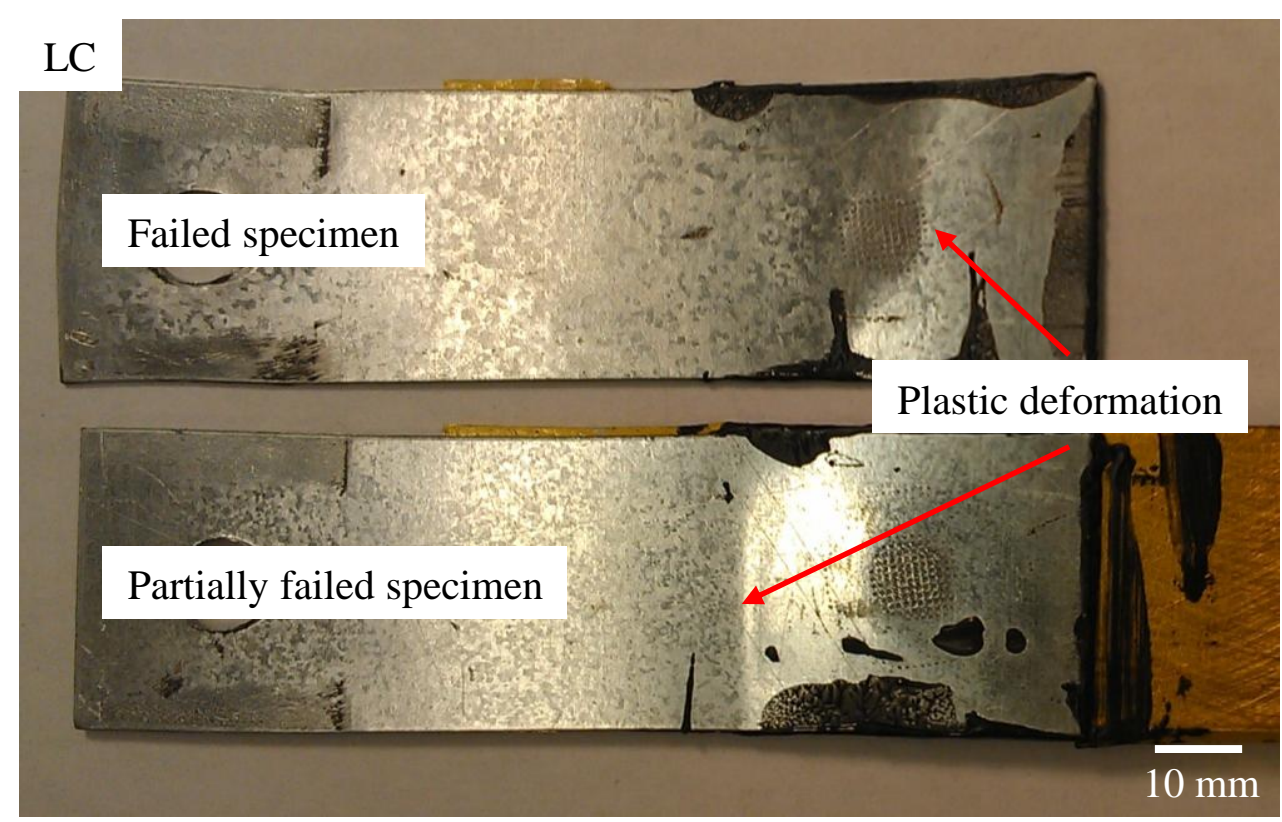

(b)

Figure 14. Plastic deformation patterns of the steel sheets along the crack fronts (a) in the failed and partially failed specimens under quasi-static loading conditions and (b) in the failed and partially failed specimens under low-cycle loading conditions. 


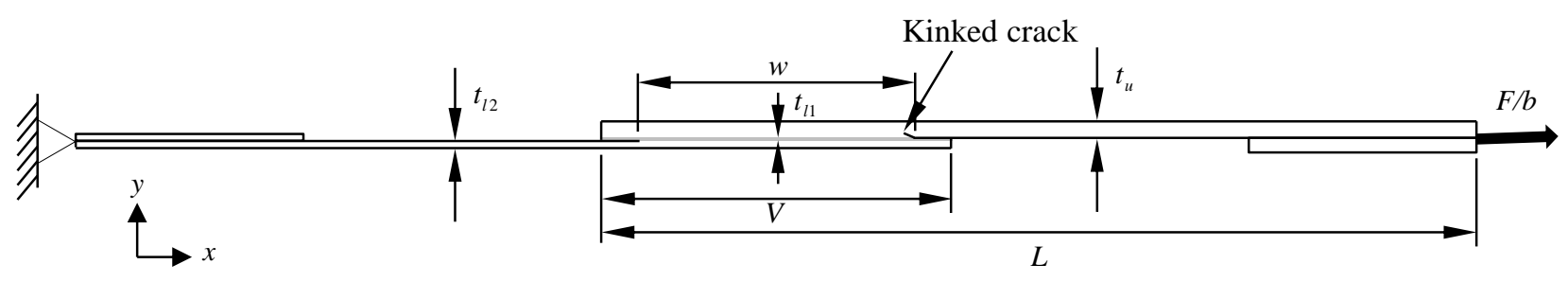

(a)

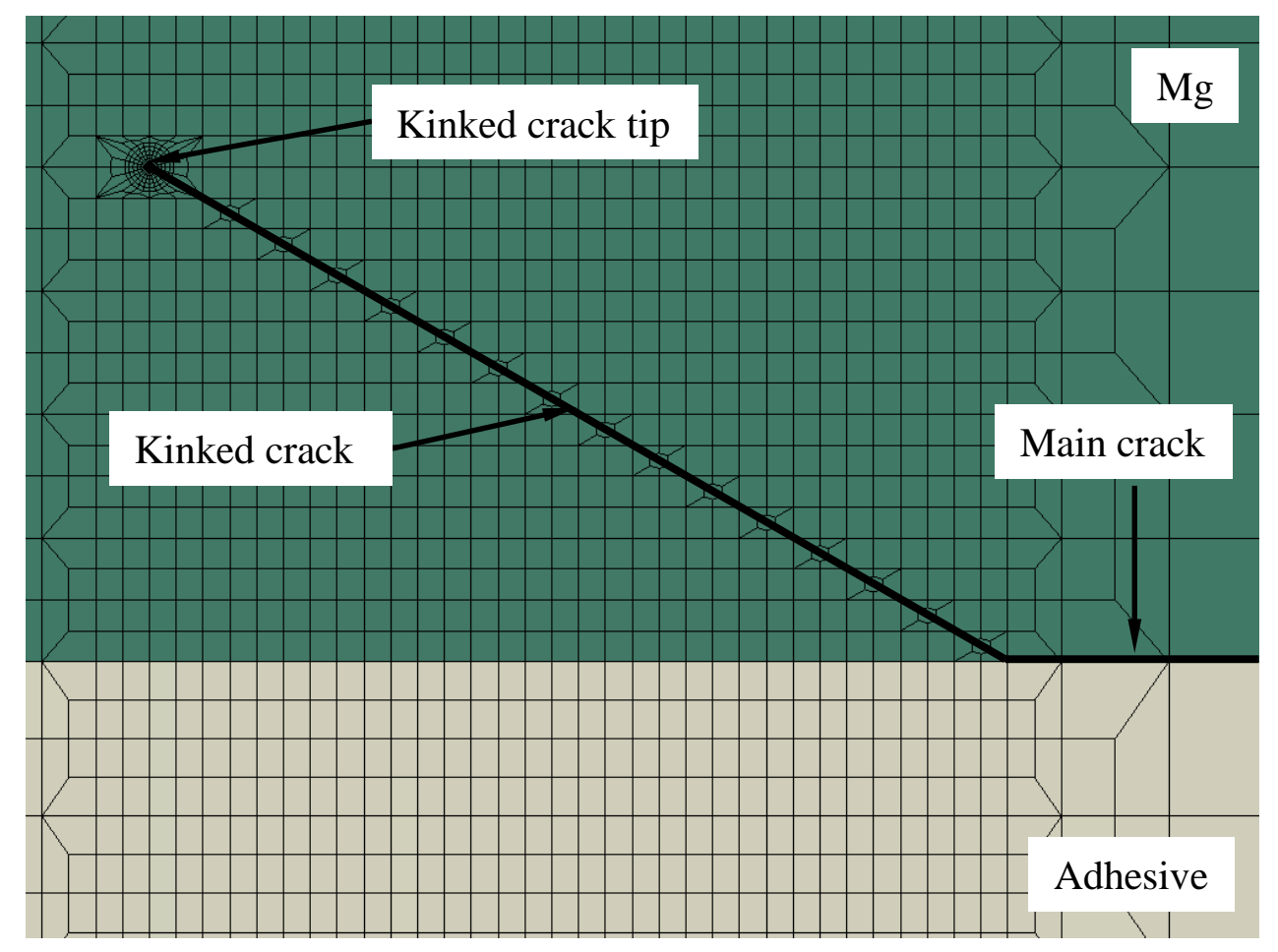

(b)

Figure 15. (a) A schematic of a two-dimensional finite element model of an adhesive-bonded lap-shear specimen with a kinked crack with the boundary and loading conditions. (b) A close-up view of the finite element mesh near the right crack tip showing the preformed crack and the kinked crack [14]. 


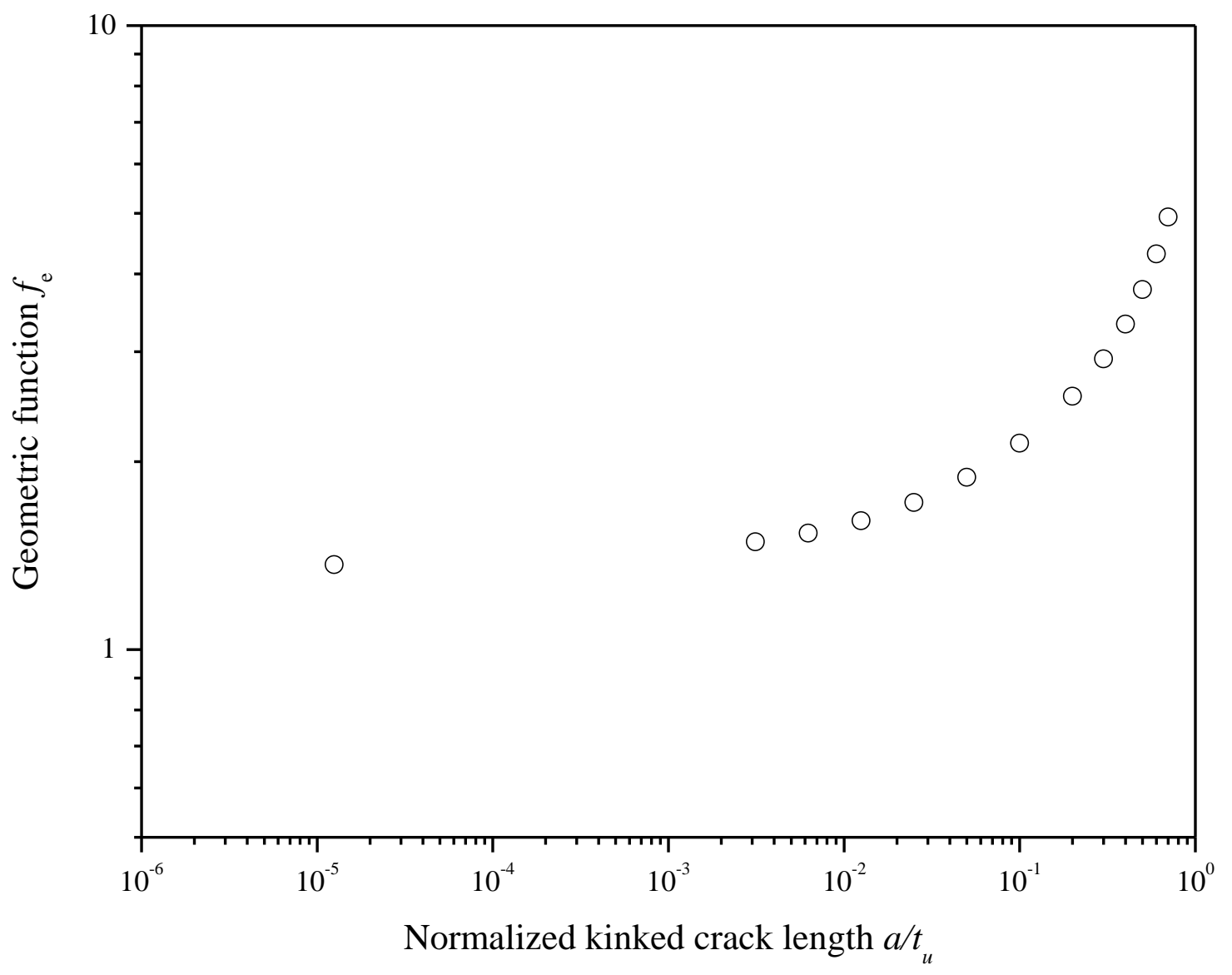

Figure 16. The computational results for $f_{\mathrm{e}}$ in the log-log scale as a function of the normalized kink length $a / t_{u}$ for the lap-shear specimens failed in the kinked crack failure mode. 